Article

\title{
Nuclear Isoforms of Neurofibromin Are Required for Proper Spindle Organization and Chromosome Segregation
}

\author{
Charoula Peta, Emmanouella Tsirimonaki, Dimitris Samouil, Kyriaki Georgiadou and \\ Dimitra Mangoura *
}

Basic Research Center, Biomedical Research Foundation of the Academy of Athens, 4 Soranou Ephessiou, 11527 Athens, Greece; p.char0ula@gmail.com (C.P.); etsirimon@bioacademy.gr (E.T.);

jimsam5@hotmail.com (D.S.); kikigeo98@gmail.com (K.G.)

* Correspondence: mangoura@bioacademy.gr; Tel.: +30-210-659-7087

Received: 18 July 2020; Accepted: 22 October 2020; Published: 23 October 2020

check for updates

\begin{abstract}
Mitotic spindles are highly organized, microtubule (MT)-based, transient structures that serve the fundamental function of unerring chromosome segregation during cell division and thus of genomic stability during tissue morphogenesis and homeostasis. Hence, a multitude of MT-associated proteins (MAPs) regulates the dynamic assembly of MTs in preparation for mitosis. Some tumor suppressors, normally functioning to prevent tumor development, have now emerged as significant MAPs. Among those, neurofibromin, the product of the Neurofibromatosis-1 gene (NF1), a major Ras GTPase activating protein (RasGAP) in neural cells, controls also the critical function of chromosome congression in astrocytic cellular contexts. Cell type- and development-regulated splicings may lead to the inclusion or exclusion of NF1exon51, which bears a nuclear localization sequence (NLS) for nuclear import at G2; yet the functions of the produced NLS and $\triangle$ NLS neurofibromin isoforms have not been previously addressed. By using a lentiviral shRNA system, we have generated glioblastoma SF268 cell lines with conditional knockdown of NLS or $\triangle$ NLS transcripts. In dissecting the roles of NLS or $\triangle$ NLS neurofibromins, we found that NLS-neurofibromin knockdown led to increased density of cytosolic MTs but loss of MT intersections, anastral spindles featuring large hollows and abnormal chromosome positioning, and finally abnormal chromosome segregation and increased micronuclei frequency. Therefore, we propose that NLS neurofibromin isoforms exert prominent mitotic functions.
\end{abstract}

Keywords: neurofibromin; neurofibromatosis; astral microtubules; astrocyte; glioblastoma; spindle assembly; chromosome positioning

\section{Introduction}

The ability of tubulins to rapidly form highly dynamic noncovalent polymers, the microtubules (MTs), has bestowed on them essential functions for the constant yet ever changing needs for spatial organization of cells, in order to execute critical processes, such as attaining function-coupled shapes, directed intracellular transport, cell migration, and the most important for development and maintenance of an organism cell divisions with accurate genomic transmission. For the latter, several types of MTs organize, elongate, and orient a bipolar spindle, through which chromosomes will position at the spindle equator for faithful sister chromatid separation and then segregation to the two daughter cells [1-3]. At least three major types serve these purposes, namely, astral MTs radiating from the centrosomes to position and orient the spindle through a protein machinery anchored to the cell cortex, microtubule bundles to link chromosome kinetochores to spindle poles (K-fibers), and interpolar bundles to elongate the spindle [4-6]. 
Accordingly, multitudes of structurally different proteins associate with MTs (MT-associated proteins, MAPs) to regulate their nucleation, polymerization, organization, bundling, and crosslinking in preparation for and completion of mitosis [7]. The availability of mitotic MAPs is tightly regulated by coordinated transcription, as well as by cell cycle-dependent post-translational modifications, most often phosphorylations that control protein trafficking, homeostasis, and inter- or intramolecular interactions [8-11]. As aberrations in any of these processes may lead to aneuploidy and further on to tumorigenesis, the ability of MAPs to modulate MT dynamics is recognized for its prognostic value in cancers, and as a sensible target for manipulations of microtubule-targeting cancer chemotherapy agents [12,13].

In this context, several MAPs have been described as oncogenes or as tumor suppressors and correspondingly several proteins, identified as such, were found to function as MAPs. Evidently, knockdown of tumor suppressor genes, such as adenomatous polyposis coli (APC) [14], PTEN [8], NF2, [15], BRCA1 [16], RASSF1A [17], NF1 [18], and TP53 [19,20], often leads to defective mitotic spindle assembly and chromosome segregation errors. Given the usually compromised ability for DNA repair and the increased replication stress in these genetic backgrounds, the resulting aneuploidy may additionally feed chromosomal instability (CIN) [14,16,21,22] and thus rapid evolution of karyotypes with clonal expansion advantages and tumorigenesis [23-28]. Another typical characteristic of such tumor suppressors is the presence of a nuclear localization signal (NLS) in their amino acid sequence, which regulates both their timely nuclear import in preparation of mitosis and their release during spindle assembly [29-31].

We have recently shown that neurofibromin functionally belongs in the group of tumor suppressors with MAP properties that localize on the spindle and regulate chromosome congression at the metaphase plate [18]. More specifically, association of neurofibromin with MTs was first established by confocal microscopy and the molecule was proposed to act as a MAP through a small segment (residues 815-834), bearing in silico homology to MAP2 and Tau [32]. Since then, additional approaches, including co-immunoprecipitations, co-purifications, in vitro microtubule assembly, and affinity precipitations, have further documented this interaction [18,33-36]. Unfortunately, the full length cDNA, encoding this large, multidomain, and multifunctional protein (Scheme 1), has not been possible to obtain in a plasmid, and structural information remains limited to the RasGAP-related domain (GRD) [37] and the Sec-PH domain [38].

Neurofibromin is encoded by the NF1 gene, mutations of which cause Neurofibromatosis type 1 (NF-1), a common, complex multisystem, familial cancer predisposition syndrome [39]. Neurofibromin is ubiquitously expressed early in development, while in the adult remains prominent in neural cells, namely, neurons, astrocytes, and Schwann cells; hence the most severe symptoms of NF-1 stem from these cell types $([39,40]$ and refs therein). In particular, high grade gliomas (anaplastic, glioblastoma-GBM) are more frequent in adults with NF-1, which have five times greater risk for GBM than the general population [39]. Moreover, NF1 is the fifth most commonly mutated gene in sporadic glioblastoma [41]. This great mutation rate of the NF1 gene that has made its cloning impossible, is highlighted by the 2800 , most often truncating or nonsynonymous, different mutations identified to date, yet with few genotype-phenotype correlations postulated [42,43]. Confirmation of causative mutation with molecular diagnosis, a task complicated by 15 pseudogenes and no mutational hot spots, does not offer help for prognosis or treatment and the challenge to correlate genotype-phenotype in this disease of uncontrolled cell growth and tumorigenesis remains largely unmet.

The quest for genotype-phenotype correlation is complicated by developmental stage- and cell type-specific alternative splicing events of the NF1 gene. Exon 31 (former 23a) is skipped in CNS neurons early on (transcript GRDI), whereas it is retained in astrocytes (GRDII) [44]. This exon corresponds to the center of the RasGAP-related domain (GRD) of neurofibromin, through which neurofibromin inactivates Ras. Due to the central role of Ras in many cellular functions and in carcinogenesis, GRDs have received high attention; they are functional RasGAPs when overexpressed in vitro [45] and, as we showed, in vivo [34], but no significant rescue capacity of GRDs alone has 
been shown for NF-1 tumor paradigms [46,47]. Instead, and along this direction, the importance of other neurofibromin domains (Scheme 1) in the allosteric regulation of GRD, has been established. Indeed, collective experimental evidence after overexpression of specific domain combinations has postulated that neurofibromin domains may bind each other [48], as well as, multiple proteins to coordinate Ras signalling $[34,46,47,49,50]$. For example, in glioblastoma cells stably overexpressing the $\mathrm{N}$-terminus half (Cysteine/Serine Rich domain (CSRD) plus GRD), PKC-dependent phosphorylation of CSRD increases interactions with the actin cytoskeleton to regulate the Ras-GAP activity of GRD and suppresses Ras-dependent proliferation [49]. The clinical significance of these findings was directly postulated when large cohorts of NF-1 patients, heterozygous for nonsynonymous mutations of a five-amino acid stretch in the CSRD, were found to have high, $>50 \%$, predisposition to malignancies as compared to the general NF-1-affected population [42,43].

(a) NLS NF1 transcripts

\begin{tabular}{|l|l|l|l|l|l|}
\hline GRDII & Ex 303132 \\
\hline & EX 3032 & Exon 33 \\
\hline
\end{tabular}

(b) $\triangle$ NLS NF1 transcripts

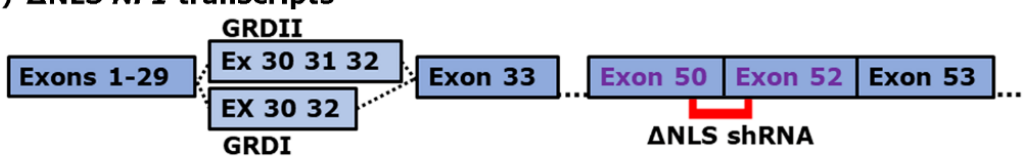

(c) Neurofibromin (domains)

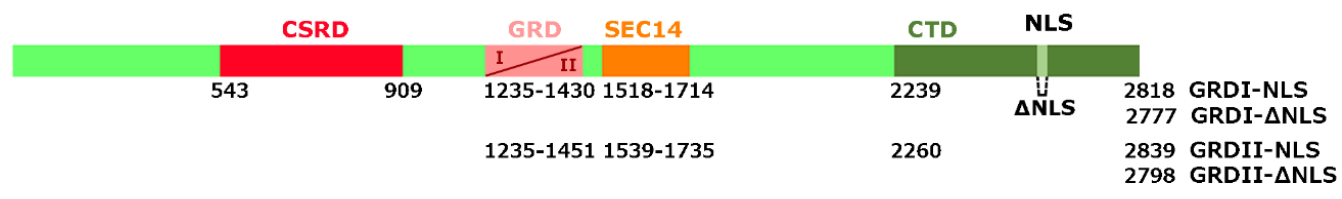

Scheme 1. Schematic representation of NF1 transcripts and neurofibromin domains. (a) and (b) depict alternative spliced events in the NF1 gene that produce NLS and $\triangle N L S$ transcripts and indicate the sequences that are targeted by the used shRNAs. (c) Neurofibromin domains are depicted in proportionate size and location: CSRD, Cysteine/Serine-Rich domain; GRD GAP-related domain (RasGAP); SEC14 Yeast Sec14p-like domain; CTD C-Terminal domain and NLS Nuclear localization sequence. Numbering of amino acids throughout the text corresponds to GRDI-NLS neurofibromin (Ensemble transcript NF-201).

Exon 51 (former 43) in the C-terminus domain of neurofibromin (CTD) may also be alternatively transcribed; in the corresponding sequence of 41 amino acids (2518-2559) lies centrally a bipartite NLS sequence (2534-2550). We first identified this NLS in silico and documented experimentally that most neurofibromin molecules reside in the nucleus of neural cells [51]. Later genetic analysis revealed that NLS-NF1 transcripts are highly expressed in the tissues in which neurofibromin expression remains high in the adult and which are implicated in NF-1- pathology, that is in neural tissues [52]. In subsequent studies on the function of the NLS in primary astrocytes and glioblastoma cells [18], which primarily express NLS transcripts, we provided the mechanism and purpose for a regulated nuclear import of endogenous, full length neurofibromin during the cell cycle: a. at late $\mathrm{S}$ phase neurofibromin synthesis increases, and PKC $\varepsilon$-phosphorylations on the NLS-adjacent Ser2808 mobilize the molecule to shuttle by the Ran/importin system that requires an NLS into the nucleus (now also confirmed in cancer breast cells [53]); b. neurofibromin localizes on centrosomes and on the spindle throughout mitosis; and c. siRNA-depletion of all NF1 transcripts leads to errors in chromosome congression. As further established by phospho-ablating or -mimetic constructs of CTD \pm NLS [18], only NLS isoforms have the ability to shuttle in and out the nucleus and therefore these congression errors may be attributed mostly to depletion of NLS-neurofibromin. However, beyond these studies, no other information exists on the properties and functions of NLS or $\triangle$ NLS neurofibromin isoforms. 
Therefore, we have launched a program to genetically manipulate cells to express either NLS or $\triangle$ NLS transcripts, and thus neurofibromin isoforms, using transcript-specific shRNAs, and have now addressed whether inclusion or not of the amino acids encoded by exon 51 , suffices to produce a different MAP.

\section{Materials and Methods}

\subsection{NF1 Transcript Knockdown with shRNA Lentiviruses}

In order to observe the effects of NLS- and $\triangle$ NLS- neurofibromin isoforms after knockdown of their respective NF1 transcript (Scheme 1) over a long time and many cell divisions while increasing reproducibility of results, we chose to interfere with the mRNA production of NLS and $\triangle N L S$ NF1 transcripts [52], by generating for each transcript shRNA constructs, which are capable of DNA integration [54]. Thus, short hairpin RNAs against sequences within exon 51 or against the exon 50-52 junction sequences (Ensemble, ENSG00000196712) were designed in order to degrade NLS or $\triangle$ NLS NF1 transcripts (Scheme 1a,b, respectively, using the Biosettia (San Diego, California, USA), Invivogen (Toulouse, France) and Hannon Lab (CRUK Cambridge Institute, UK) (GSHL) platforms and synthesized by Macrogen (Seoul, Korea). Each target sequence was used in a complementary pair of oligos where the sense and antisense sequence of interest formed the $21 \mathrm{nt}$ stem of the shRNA. The oligos also bore flanking miR30 sequences and a 6 nt loop [55].

Specifically, the shRNA oligos were used to generate the insert shRNA fragment by the annealing method, which allowed us to subclone it into the XhoI/EcoRI- digested lentiviral, tet-inducible RFP-vector pINDUCER10 backbone [56] (Addgene, LGC Standards, Teddington, UK) and produce the RFP-Tet-NLS-pINDUCER10 and RFP-Tet- $\triangle$ NLS-pINDUCER constructs. For lentivirus production, HEK293T cells, grown to 60\% confluency in Dulbecco's modified Eagle medium (DMEM, ThermoFisher, Waltham, MA, USA) and 10\% fetal bovine serum (FBS, Biowest, Nuaille, France) were co-transfected with the generated plasmids or mock plasmid, along with the VSV-G (pMD2.G, Addgene) and gag-pol (pCMV-dR8.91, Applied Biological Materials Inc., Richmond, BC, Canada) expression plasmids. Lentivirus-containing medium was collected after $48 \mathrm{~h}$, spun at $4500 \mathrm{rpm}$ for $20 \mathrm{~min}$, filtered through a $20 \mu \mathrm{m}$ syringe filter and used to transduce SF268 cells (passage 60, ATCC, LGC Standards GmbH, Germany) for $48 \mathrm{~h}$, and then the medium was replenished with fresh medium for another $24 \mathrm{~h}$. At this point cells were treated with $10 \mathrm{mM}$ of doxycycline to induce shRNA expression and with $5 \mu \mathrm{M}$ puromycin to select transduced cells and generate cell lines stably expressing the candidate shRNAs. A week later cells were sorted (mean \pm 1 standard deviation) using Fluorescence Assisted Cell Sorting (FACS Facility, BRFAA), and banked at different passages in 5\% DMSO, 10\% glycerol, 20\% DMEM, and $65 \% \mathrm{FBS}$ at $-135^{\circ} \mathrm{C}$. All cell lines were maintained in culture with $10 \% \mathrm{FBS}, 2 \mathrm{mM}$ L-glutamine and $1 \%$ penicillin/streptomycin at $37^{\circ} \mathrm{C}$ and $5 \% \mathrm{CO}_{2}$.

Transcript and protein knockdown was confirmed with immunofluorescence for $\triangle \mathrm{NLS}$ isoform nuclear expression (e.g., Figure 1), and with qPCR and Western blotting (WB) for both $\triangle$ NLS and NLS transcript and isoform expression (e.g., Supplementary Figure S1a,b). More specifically, total RNA from $4 \times 10^{6}$ cells from each cell line post FACS sorting was isolated with TRI Reagent (Sigma, St. Louis, MO, USA), and reverse transcribed with M-MuLV Reverse Transcriptase (Genscript, Piscataway, NJ, USA) and random primers (Invitrogen, Carlsbad, CA, USA), as previously described, e.g., [18,57]. Every sample within an experiment was reverse transcribed at the same time and cDNAs were stored at $-80{ }^{\circ} \mathrm{C}$ until used. One hundred ng of cDNA were used in a $10 \mu \mathrm{L}$ reaction mixture, consisting of NLS (5'-GAAGTTGCTTGGAACAAGGAAAAGT-3' , 5' -TCATAATCAGTTTCTGCTACTCTCC-3') or $\triangle$ NLS (5'-GAAGTTGCTTGAAACTCAGAGGA-3', 5' -AACACAACACTGGCCTCTGCTAA-3') specific primers at $0.5 \mu \mathrm{M}$ and Kapa SYBR Fast Universal qPCR Master Mix (Roche, Switzerland). Empty vector DNA was used as a non-template control. Quantitative PCR (qPCR) was performed using the Roche LightCycler ${ }^{\circledR} 96$ System (Basel, Switzerland), under the following conditions: preincubation at $95^{\circ} \mathrm{C} \times 5 \mathrm{~min}$, amplification for 45 cycles at $95^{\circ} \mathrm{C} \times 15 \mathrm{~s}$ and then at $60^{\circ} \mathrm{C} \times 60 \mathrm{~s}$, and melting at 
$95^{\circ} \mathrm{C} \times 10 \mathrm{~s}, 65^{\circ} \mathrm{C} \times 60 \mathrm{~s}$, and $97^{\circ} \mathrm{C} \times 1 \mathrm{~s}$. GAPDH was used as reference gene. Reactions were set up from all three cell lines in triplicate from at least three separate experiments corresponding to different cDNA isolation dates and data were analyzed using the relative quantification 2- $\Delta \Delta C T$ method [58].

Western blot analysis was essentially done as we have previously described $[18,49,57,59,60]$ : equal amounts $(60 \mu \mathrm{g})$ of total cell homogenates in radioimmunoprecipitation (RIPA) buffer, supplemented with protease and phosphatase inhibitors, were resuspended in $5 \times$ Laemmli buffer and proteins were separated with Sodium dodecyl sulfate-polyacrylamide gel electrophoresis (SDS-PAGE). After electrophoresis, proteins were transferred into nitrocellulose membranes and probed with primary antibodies. Immunoreactivity was visualized with the appropriate species-specific antibody conjugated to horseradish peroxidase (HRP), enhanced chemiluminescence, and film exposure; films were then scanned and densitometry analysis was performed with the ImageJ software.

Using this methodology, we chose the following sequences as both fulfilling optimal criteria and efficiently reducing by $85-95 \%$ mRNA levels: for the NLS NF1 transcript ${ }^{7609}$ GAAATGGAATCAGGG ATCACA $^{7629}$ and for the $\triangle$ NLS ${ }^{7546}$ TGCTTGAAACTCA GAGGATTTCC ${ }^{7552}$, respectively (Supplementary Figure S1a); the 9:1 ratio [18] of GRDII:GRDI was not affected (not shown). As expected, total neurofibromin protein levels, assessed by densitometric analysis (ImageJ) of WBs using polyclonal antibodies sc-13023 and H-300 (Santa Cruz Biotechnology, Heidelberg, Germany), decreased by $30 \%$ in $\triangle$ NLS-SF268 and by $18 \%$ for NLS-SF268. Almost identical results for each isoform were obtained after silver staining of immunoprecipitated neurofibromin, albeit using different antibodies, all raised against the N-terminus of neurofibromin: rabbit polyclonals sc- 68 and sc- 13032 recognized neurofibromin in lysates of $\triangle$ NLS cells, but only partially in NLS cell lysates, whereas the monoclonal sc-20016 recognized NLS isoforms at levels compatible with WB results, but $\Delta$ NLS isoforms only faintly (Supplementary Figure S1c).

\subsection{Immunocytochemistry}

Immunofluorescence analyses were performed as previously described by us [18,51,60]. Briefly, cells were plated on glass coverslips and grown to desired confluency; prior to a 10 min extraction with $0.2 \%$ Triton X-100 and fixation with paraformaldehyde (PFA), cells were treated with the protein crosslinker 3,3'-dithiodipropionic acid di(N-hydroxysuccinimide ester) (DSP, ProteoChem, Hurricane, UT, USA) in order to best visualize cytoskeleton and associated proteins. In some experiments, extraction with 3 min exposure to $0.1 \%$ Triton X-100 was performed after PFA fixation and in others, coverslips were immersed in $-20^{\circ} \mathrm{C}$ methanol for $10 \mathrm{~min}$, all prior to blocking with $3 \%$ appropriate animal sera and exposure to primary antibodies for $3 \mathrm{~h}$. Primary antibodies used for detection of: neurofibromin, namely mouse monoclonals sc-376886 and sc-20016, and the polyclonals sc-68 and sc-13032 were purchased from Santa Cruz; $\beta$-tubulin, mouse monoclonal T4026 was from Sigma (St Louis, MO, USA); and $\gamma$-tubulin, ab11316 mouse monoclonal from Abcam (Cambridge, UK). Visualization of primary antibody binding was accomplished using the appropriate secondary antibodies conjugated to Texas Red ${ }^{\circledR}$ (GeneScript, Piscataway, NJ, USA), Cy ${ }^{\mathrm{TM} 5}$, or fluorescein (Jackson ImmunoResearch, Pennsylvania, USA); F-actin was visualized with Oregon Green $^{\mathrm{TM}} 488$ phalloidin (ThermoFisher, Waltham, MA, USA) and chromatin structures with Hoechst 33258 (Sigma). When indicated, cells were synchronized with a double thymidine block, as we have previously described [18].

\subsection{Imaging and Image Analysis}

\subsubsection{Fluorescence}

Fluorescence was imaged using a Leica TCS SP5 inverted confocal microscope with a motorized stage, a 63×/1.4 NA HC PL APO CS oil lens, and a Tandem Scanner (Leica Microsystems, Mannheim, Germany; Biological Imaging Unit, BRFAA), and z-stacks with $0.34 \mu \mathrm{m}$-thick z optical sections were captured for each fluorophore. When appropriate, images were connected to an extended 
focus single section, using the maximal intensity projection algorithm of the LAS AF Software (Leica Microsystems). For every experiment, samples from all three cell lines were imaged using identical microscope settings, which were set prior to capturing and after pilot screening to define the common settings at which no saturated pixels were detected in any of the samples. All images were deconvolved using the Richardson-Lucy total variation algorithm found in DeconvolutionLab2 plugin [61]. Theoretical Point-Spread Functions (PSFs) were created using the Born \& Wolf PSF model [62] from the PSFGenerator plugin.

\subsubsection{Phase Microphotographs}

Phase microphotographs of the wound healing assays were captured using a Hamamatsu Orca-ER CCD camera, connected to a Zeiss $200 \mathrm{M}$ inverted microscope equipped with a motorized stage, all controlled with the Slidebook ${ }^{\mathrm{TM}} 6.0$ software (3i, Göttingen, Germany) and analyzed using the ImageJ public domain software (NIH).

\subsubsection{Colocalization Analysis}

Colocalization analysis of $\beta$-tubulin, F-actin or $\gamma$-tubulin with neurofibromin was performed with the Volocity ${ }^{\circledR}$ 6.1.2 software (Perkin-Elmer, Seer Green, UK), using the Costes Pearson's Correlation Coefficient (PCC) algorithm [63]. Regions of interest (ROI) were drawn manually around a. cells for $\beta$-tubulin/neurofibromin b. cells or lamellipodia for F-actin/neurofibromin, and c. centrosomes for $\gamma$-tubulin/neurofibromin colocalizations. Within ROIs, this software applies thresholding [64], and then calculates and scores the extent of overlap between fluorophores within a range of 1 , if a perfect positive correlation, to -1 , if a perfect but inverse correlation; 0 represents a random distribution. PCC means were automatically calculated from the generated scattered plots and exported for every single plane in an excel file; such examples are shown in Supplementary Figure S2 and correspond to the images shown in Figure 1.

\subsubsection{Fluorescence Intensity}

Fluorescence intensity of $\beta$-tubulin signals from the spindle, or from astral or cytosolic MTs, and of $\gamma$-tubulin signals from centrosomes was measured using IMARIS ${ }^{\circledR}$ 8.3.1 software (Bitplane, Zürich, Switzerland) in 3D image reconstructions. The IMARIS surface tool (0.2 $\mu \mathrm{m}$ Gaussian Filter) was used to render solid surfaces of spindles and centrosomes, regardless of cell orientation (e.g., Figure 4d) and measurements were based on the mean intensity, whereas volume was automatically calculated in $\mu \mathrm{m}^{3}$.

\subsubsection{Microtubule Intersection Analysis}

Microtubule intersection analysis was performed using ImageJ Sholl Analysis [65], an algorithm that creates a series of concentric circles around a specified focus (in this case the center of a nucleus, e.g., Figure 2) and then counts how many times microtubules intersect the sampling circles, on cells fixed with DSP and PFA or with methanol and immunostained for $\beta$-tubulin. The area of the nucleus, as defined from Hoechst fluorescence, was excluded from the analysis. Results are exported as both TIFF images, where each concentric circle is color-coded according to their Sholl profile and the detected number of intersections (yellow hues indicates highest number of intersections), and as numerical data in an excel file, for statistical analysis.

\subsubsection{Spindle Length and Orientation}

Spindle length and orientation analysis was also performed using ImageJ in z-stacks of confocal planes of cells in metaphase. Spindle length was determined as the distance between the two centrosomes, visible after $\gamma$-tubulin immunostaining. For this, the two planes with the strongest signal from each pole were recorded, the number of intermediate planes between these two was added and the sum multiplied by 0.34 (plane thickness in $\mu \mathrm{m}$ ) to calculate the side of an orthogonal triangle; 
the other side was the distance in $\mu \mathrm{m}$, calculated as the distance of the poles on maximal intensity projection of these stacks, and the spindle length was its hypotenuse. The angle was then calculated by the cosine between the side of $\mathrm{z}$-stack thickness and the hypotenuse.

\subsubsection{Astral Microtubule Length}

Astral microtubule length analysis was performed using the ImageJ plugin Single Neurite Tracer [66]: each visible astral microtubule was traced across z-stack in a semi-automated manner, that is, after manually defining the starting and ending point of microtubules. When preparing maximal intensity projections for Figures depicting spindles, e.g., Figure 4, astral microtubules were not readily visible without enhancing the fluorescence to points that the rest of the spindle was oversaturated with color. Therefore, the astral microtubule area is presented with enhanced brightness in Supplementary Figure S4.

\subsection{Wound Healing Assay}

For the wound healing assay, cells at $60-70 \%$ confluency were detached by trypsin treatment and seeded on glass bottom culture dishes (MatTek, Ashland, MA, USA). When cells formed a monolayer ( $\geq 90 \%$ confluency), a wound was made by scratching a line with a white tip across the bottom of the dish. Cells were rinsed gently with PBS, medium was replenished and cultures were photographed in several areas under phase in a Zeiss 200M inverted microscope; coordinates of these areas were marked with the appropriate stage Slidebook ${ }^{\mathrm{TM}}$ tool and the same areas were photographed again after $24 \mathrm{~h}$. Slidebook ${ }^{\mathrm{TM}}$ images, exported as TIFFs, were then used to calculate the wound area by manually tracing the cell-free area in captured images using ImageJ. For analysis of the microtubule-organizing center (MTOC) and nucleus positions during migration, cells cultured on coverslips were immunostained with $\beta$-tubulin and Hoechst, respectively, as described above. For time-lapse video microscopy, cells were resuspended in $35 \mathrm{~mm}$ glass bottom dishes (MatTek) and left to grow into a monolayer, in normal $\mathrm{CO}_{2}$ and temperature. The monolayer on the glass part of the dish was scratched, as described above. After $14 \mathrm{~h}$, the cells were rinsed and their medium was replaced by Leibovitz's L15 medium without phenol red (ThermoFisher); phase photographs were shot every 2 min for an observation period of $4 \mathrm{~h}$ and the results were compacted as a video with the appropriate Slidebook ${ }^{\mathrm{TM}}$ tool.

\subsection{Statistics}

All experiments were performed five to ten times with similar results and numerical data were analyzed by ANOVA, using the GraphPad Prism 8 software and a set statistical significance level $(p)$ of 0.05 . Graphs were generated with the same software and images were organized using Adobe Photoshop.

\subsection{Databases}

The following databases have been used: genome browser; https://www.ensembl.org/protein alignment; https://www.ebi.ac.uk/Tools/psa/emboss_water/ (Cambridge, UK); and prediction of serine, threonine or tyrosine phosphorylation sites, NetPhos 3.1 Server http://www.cbs.dtu.dk/services/ NetPhos (DTU Bioinformatics, Lyngby, Denmark).

\section{Results}

3.1. Differential Subcellular Distribution of Neurofibromin NLS and $\triangle N L S$ Isoforms and Associations with the Actin and Tubulin Cytoskeletons affect Cytosolic MT Organization and Cell Migration Patterns

To further address the mechanism by which neurofibromin regulates chromosome congression [18] and considering together that a. the major cellular target in NF-1 for abnormal proliferation and carcinogenesis is the astrocyte $([39,40], \mathrm{b}$. neurofibromin accumulates in the nucleus in a Ran-dependent manner at late S/G2, and c. the higher expression of NLS- over $\triangle$ NLS -NF1 transcripts in astrocytes, we 
sought to evaluate separately the roles of $\triangle$ NLS- and NLS-isoforms in spindle assembly in an astrocytic cell context. Thus, we generated SF268 glioblastoma cell lines that stably express, under the control of doxycycline, shRNAs specifically designed to degrade either the GRDI- or GRDII- $\triangle$ NLS transcripts or the GRDI- and GRDII-NLS-NF1 transcripts (Scheme 1; for simplicity, we will refer to those as NLS-SF268 cells and $\triangle$ NLS-SF268 cells, respectively). Because we have previously established colocalization of endogenous neurofibromin with the microtubule (MT) and F-actin cytoskeletons [49,51,60], we first proceeded with confocal image analysis of cells immunostained for $\beta$-tubulin and neurofibromin and co-stained for filamentous actin with FITC-phalloidin and chromatin/chromosomes with Hoechst 33258. Our analyses included intensity assessment of $\beta$-tubulin and neurofibromin fluorescence signals using IMARIS, and $\beta$-tubulin/neurofibromin and F-actin/neurofibromin colocalization quantitation using Volocity, as described in Materials and Methods. In order to best preserve filamentous cytoskeleton structures and their associated proteins, cells were treated with the crosslinker DSP and then extracted with Triton X-100 prior to fixation [18,51,67].

Parental SF268 cells, which express both NLS- or $\triangle$ NLS-isoforms, typically [18] show pools of endogenous neurofibromin to colocalize with cytoplasmic microtubules and the distinctly organized MTOC (Figure 1a, long arrows), and the mitotic spindle (Figure 1a, yellow arrows), as well as with F-actin, mainly at the cell cortex and lamellipodia (Figure 1a, small arrows). About 35\% of neurofibromin immunofluorescence derives from the nucleus (Figure 1a, asterisk), part of which is contributed by the nuclear envelope through interactions with the nuclear intermediate filament lamin A and the rest from associations with non-chromatin nuclear structures [18]. As expected, nuclear localization greatly differed among the genetically modified cell lines, with $\triangle$ NLS neurofibromins practically absent from the nucleus of $\triangle$ NLS-SF268 cells at interphase, while NLS isoforms (NLS-SF268 cells) retained various intensity levels in the nucleus, as seen in the parental cells (asterisks in Figure $1 \mathrm{~b}$ versus a and c; Table 1).

\section{(a) SF268}
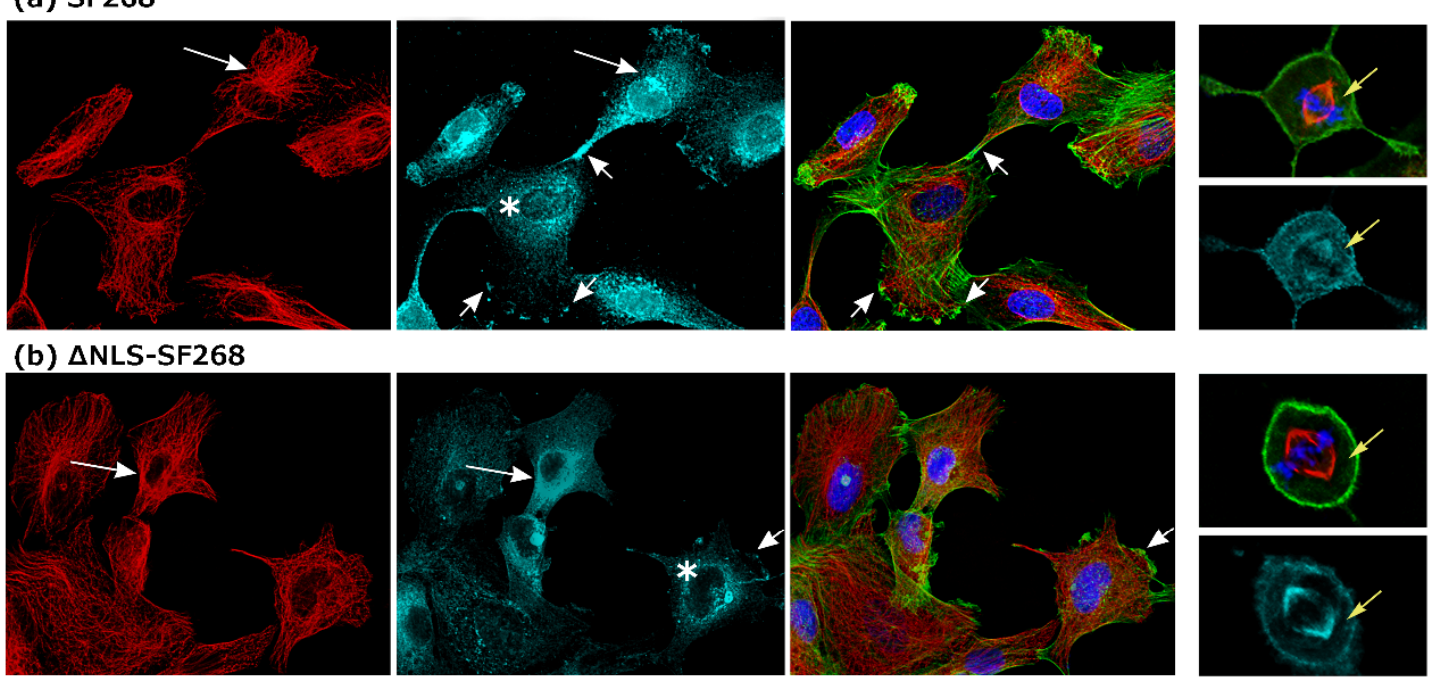

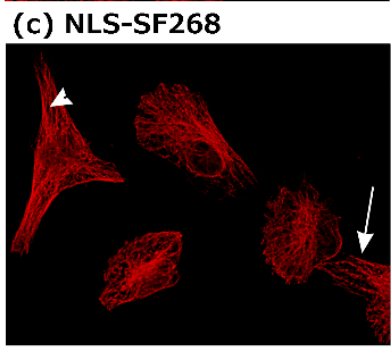

$\beta$-Tubulin

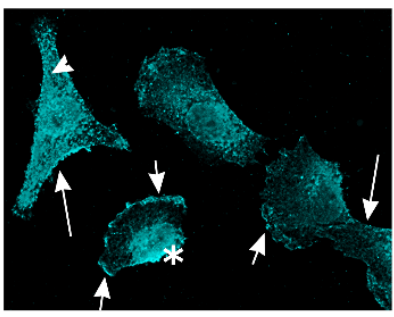

Neurofibromin

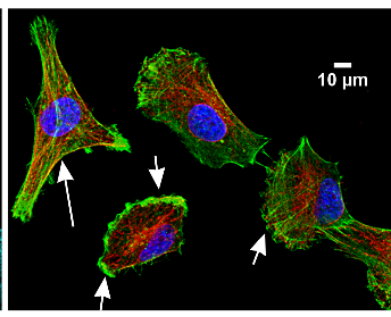

$\beta$-Tubulin F-actin Hoechst

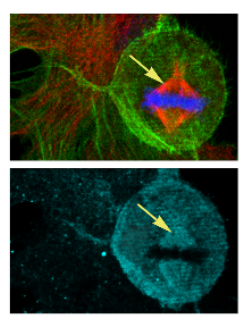
B-Tubulin F-actin Hoechst
Neurofibromin

Figure 1. Subcellular localization and co-localization with $\beta$-tubulin or F-actin of endogenous neurofibromins differ in cells genetically modified with shRNA knockdown of non-NLS or NLS NF1 
transcripts and express either $\triangle$ NLS or NLS neurofibromin, respectively. Asynchronous cells, treated with the cross-linker DSP, extracted with Triton X-100, and fixed with PFA, were quadruply stained for $\beta$-tubulin (red), neurofibromin (cyan), F-actin (green), and chromatin (blue), as described in Methods. Panels show representative confocal deconvolved images at interphase (first three columns) and at metaphase (last column) of (a) SF268 naïve cells, (b) $\Delta$ NLS-SF268 cells, and (c) NLS-SF268 cells. Detailed description is provided in the text. Images are the maximal intensity projection of $0.34 \mu \mathrm{m}$ confocal planes that include all F-actin and $\beta$-tubulin signals; representative single planes and corresponding fluorochrome correlation scattered plots are presented in Supplementary Figure S2.

Table 1. Quantitative intensity and colocalization analysis.

\begin{tabular}{|c|c|c|c|c|c|c|}
\hline & \multirow{3}{*}{$\begin{array}{l}\text { Nucleus } \\
\begin{array}{l}\text { Neurofibromin } \\
\text { Intensity }\end{array}\end{array}$} & \multicolumn{4}{|c|}{ Cytosolic Area } & \multirow{3}{*}{$\begin{array}{l}\text { Spindle } \\
\text { Colocalization, } \\
\beta \text {-Tubulin and } \\
\text { Neurofibromin }\end{array}$} \\
\hline & & \multicolumn{2}{|c|}{$\begin{array}{c}\text { Colocalization, } \\
\text { F-Actin and Neurofibromin }\end{array}$} & \multirow{2}{*}{$\begin{array}{l}\text { Colocalization, } \\
\beta \text {-Tubulin and } \\
\text { Neurofibromin }\end{array}$} & \multirow{2}{*}{$\begin{array}{l}\beta \text {-Tubulin } \\
\text { Intensity }\end{array}$} & \\
\hline & & All & Lamellipodia & & & \\
\hline SF268 & $9.80 \pm 1.16$ & $0.17 \pm 0.01$ & $0.41 \pm 0.07$ & $0.23 \pm 0.02$ & $28.83 \pm 0.47$ & $0.46 \pm 0.04$ \\
\hline$\Delta$ NLS-SF268 & $2.21 \pm 0.30^{* * *} \downarrow$ & $0.07 \pm 0.04 * \downarrow$ & $0.16 \pm 0.05^{* * * *} \downarrow$ & $0.21 \pm 0.02+$ & $73.75 \pm 3.06^{* * * * \uparrow}$ & $0.52 \pm 0.02+$ \\
\hline NLS-SF268 & $9.32 \pm 0.80+$ & $0.26 \pm 0.01 * \uparrow$ & $0.55 \pm 0.04 * \uparrow$ & $0.33 \pm 0.01^{* * * * \uparrow} 1$ & $25.01 \pm 0.19+$ & $0.66 \pm 0.02^{* * * \uparrow} \uparrow$ \\
\hline
\end{tabular}

Colocalization of $\beta$-tubulin or F-actin and neurofibromin, was measured using Volocity and Pearson's Correlation Coefficient (PCC) on confocal images; the area of the nucleus was defined by the Hoechst staining signals. Nuclear neurofibromin intensity and the intensity of $\beta$-tubulin in the cytosolic area were measured using IMARIS on confocal images; numerical values represent the mean intensity per cell area in arbitrary units \pm SE from 40 randomly chosen cells, from each of 5 experiments. $p$ values refer to statistical differences between each genetically modified cell line and the parental SF268 cells, and arrows indicate the direction of these differences. ${ }^{1}$ the statistical difference between $\Delta$ NLS-SF268 and NLS-SF268; ${ }^{*}, p<0.05 ;{ }^{* * *}, p<0.001 ;{ }^{* * *}, p<0.0001 ; \dagger$, no significant difference.

Moreover, in cells depleted of NLS neurofibromins and thus expressing only $\triangle$ NLS neurofibromins ( $\triangle$ NLS-SF268), association of neurofibromin with F-actin was significantly limited, especially in lamellipodia that appeared less developed, as well (Figure 1b, small arrow and Table 1). In contrast, in their counterpart NLS-SF268 cells, the NLS-neurofibromin richly decorated their well-formed lamellipodia and significant increases of association with F-actin were recorded (Figure 1c, small arrows and Table 1). Association with tubulin was not significantly reduced in $\triangle$ NLS-SF268 cells, yet neurofibromin localization appeared more diffused without the typical fibrillar patterns and perinuclear concentrations (Figure 1b, long arrows and Table 1). Notably, a cytoplasmic MTOC was not readily recognized and MTs organized a dense yet non-radial network of often parallel fibers, with significantly increased $\beta$-tubulin intensity (Table 1 ). To the contrary, NLS neurofibromin colocalization with $\beta$-tubulin was significantly enhanced (NLS-SF268; Figure 1c, arrowheads; Table 1), while $\beta$-tubulin intensity was not affected (Table 1 ). Both types of neurofibromins retained colocalization with $\beta$-tubulin on the mitotic spindle (Figure 1, yellow arrows in far-right column panels and Supplementary Figure S2d), albeit colocalization levels with NLS-neurofibromin were significantly raised, as also seen with MTs in the cytosol (Table 1). Taken together, these data showed that NLS-neurofibromins exhibit greater affinity for spindle MTs and for cytosolic MTs without affecting their density, whereas $\triangle$ NLS-neurofibromins, exhibiting lesser affinity for cytosolic MTs, inversely regulated MT densities in the cytoplasm.

To substantiate the differential patterns of MT organization and $\beta$-tubulin densities, we applied Sholl analysis (ImageJ) in order to quantitate numbers and dispersion of MT intersections within each NF1-type cell. Both parameters differed among the $\Delta$ NLS-SF268 cells and the parental or NLS-SF268 cells (Figure 2). Specifically, numbers of MT intersections in SF268 and in cells expressing NLS neurofibromin were higher in the perinuclear area (inner yellow circles, Figure 2a left and right panels) and gradually reduced towards the cell periphery (green to purple circles), independent of the fixation used (Figure 2 row a1, DSP and Triton X-100 extraction; row a2, methanol). In contrast, numbers of intersections in $\triangle$ NLS-SF268 were overall significantly less, with the gradient of high-to-low concentrations (yellow to purple hues) from the perinuclear area towards the cortex significantly toned 
down (Figure 2a middle panels and b), when compared to those seen in parental SF268 and NLS-SF268 cells. Again, similar results were obtained with DSP or methanol fixation (Figure 2, middle panel in a1 versus a2 row), further corroborating the images of less radial or tufted arrangements of intracellular MTs in $\triangle$ NLS-SF268 cells (Figure 1b).
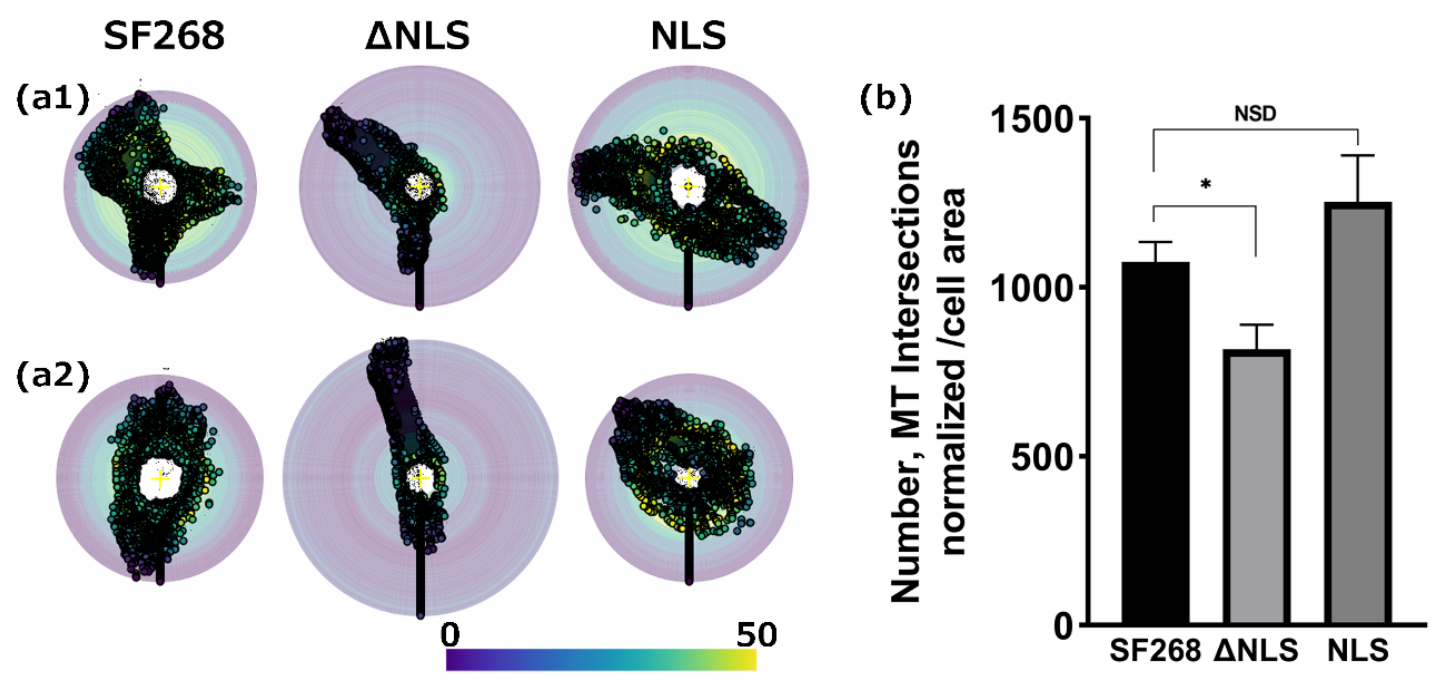

Figure 2. Knockdown of NLS neurofibromin reduces intracellular microtubule (MT) intersections. Sholl analysis on confocal images, captured after different fixations, (a1) DSP crosslinking and PFA fixation or (a2) methanol fixation, revealed that SF268 and NLS-SF268 cells showed high numbers (yellow hues) of MT intersections around the nucleus and the MTOC/centrosome area which gradually declined towards the cell periphery (yellow to light blue to purple hues), whereas $\Delta$ NLS-SF268 cells displayed lower numbers of MT intersections and almost uniform distribution along the nucleus-cortex radius. (b) Quantification of MT intersections in each genetic background, normalized per cell area. Bracketed bars represent the means and standard errors of measurements in 20 cells per cell line from each of 3 separate experiments; ${ }^{*}, p<0.05$; NSD, no significant difference.

We then investigated the different robustness of MTOC formation among $\triangle$ NLS-SF268 cells and the parental or NLS-SF268. In epithelial cells, in particular astrocytes, a most well explained paradigm of cellular polarization [68] is the relocation of the centrosome, the major MTOC, between the nucleus and the leading edge of the cell during migration, most likely in order to help provide needed, Golgi-processed proteins to the cell front along microtubules. Thus, to assess whether the ability of cells to distinctly organize and polarize their MTOCs during cell migration was affected by the expression of NLS or $\triangle$ NLS neurofibromins, we used wound healing assays. Parental and genetically modified cells, grown on glass-bottom MatTeK $35 \mathrm{~mm}$ dishes as monolayers, were scratched with a pipette tip to create a linear wound and photographed at this time and again $24 \mathrm{~h}$ later under phase-contrast (Supplementary Figure S3). This analysis showed that NLS-SF268 retained similar migration progress to parental, while $\triangle$ NLS-SF268 cells would cover only $25 \%$ of that covered by the parental cells or NLS-SF268 (Figure 3a). When positions of nuclei and centrosomes were observed in fixed cells, stained for $\gamma$-tubulin and Hoechst $12 \mathrm{~h}$ post-scratching, confocal microscopy revealed that in parental and NLS-SF268 cells centrosomes were readily positioned between the leading edge and the nucleus and directed towards the long axon of the wound, whereas $\triangle$ NLS-SF268 cells had randomly polarized centrosomes in relation to these points of reference (Figure 3, arrows in c versus b and d).

Moreover, directional movement studies (post-scratching time-lapse video microscopy, Supplementary Videos S1-S3) confirmed that NLS-SF268 cells are highly migratory and, like the parental SF268, move with a directed, multicellular movement, often following a leader cell [69]. In contrast, $\triangle$ NLS-SF268 cells moved almost as fast in terms of speed, but in a palindromic motion, thus failing to repair the "scratch wound" even after $48 \mathrm{~h}$. This is the first time that inclusion or not 
of an NLS in the neurofibromin sequence is linked to modifications of astrocytic cell migration, and, at least for $\triangle$ NLS neurofibromin, to defective centrosome positioning and cell polarity.

\subsection{Loss of NLS-Neurofibromin Leads to Defects in Spindle Length and Geometry, and Chromosome Congression at Metaphase}

As described earlier, at late S phase, NLS-NF1 transcript levels increase along with increases in neurofibromin abundance; the molecule then mobilizes, after PKCE-phosphorylation on the NLS-adjacent Ser2808, to bind to importins and accumulate in the nucleus, and to localize on the spindle throughout mitosis. Moreover, effective depletion of neurofibromin ( $>96 \%$ of protein), with an siRNA against exon 4 and thus all transcripts, causes aberrant chromosome congression with chromosomes remaining at various distances away from the metaphase plate [18]. Therefore, we next examined which type, NLS or $\triangle$ NLS-neurofibromin, was causally linked to this phenotype. For best results, we first established the average spindle length for each modified genotype and assessed congression phenotypes in relation to spindle length (Figure $4 \mathrm{a}-\mathrm{g}$ ). In pilot experiments, we established that the percentage of cells with a spindle axis almost perpendicular (vertical) to the surface of the coverslip was strictly inversely related to confluency for all, naïve or genetically modified, SF268 cells, therefore all described measurements were performed at 70-80\% confluency, when $>90 \%$ of spindles are almost horizontal [70].

As shown in Figure 4a, parental cells at metaphase and fully developed metaphasic spindles (pole to pole distance $\bar{x}=10.8 \pm 0.2 \mu \mathrm{m}$; Figure 4e) had normally congressed chromosomes at the spindle equator (white arrows), as also did NLS-neurofibromin expressing cells (Figure $4 \mathrm{~b}$, white arrows), which, however, had significantly shorter spindles (maximum length $\bar{x}=8.91 \pm 0.22 \mu \mathrm{m}$, Figure 4e). In stark contrast, these parameters were inversely regulated in cells expressing only $\triangle$ NLS-neurofibromin, which had very poorly aligned chromosomes at the equator (Figure 4c, white arrows), even when the metaphasic spindle was fully developed, at least in length $(\bar{x}=11.5 \pm 0.15 \mu \mathrm{m}$, Figure 4e). More specifically, in over $50 \%$ of cells, the majority of chromosomes appeared in rows that formed a wide belt (Figure 4c, spindles ii-iv) and in the rest formed a better defined metaphase disk of chromosomes, still, however, lacking the tight alignment (e.g., Figure 4c, spindle i) observed in parentals.

Intensity measurements in three-dimensional reconstructions of all confocal z-planes with $\beta$-tubulin and Hoechst fluorescence signals (Figure $4 \mathrm{~d}$; reconstructed spindles are those shown in a.i for SF268, in c.ii and iii for $\triangle \mathrm{NLS}$, and in b.i for NLS cells) revealed that $\beta$-tubulin intensity in the anastral spindles of $\triangle$ NLS cells (Figure $4 \mathrm{~d}$, asterisks in SF268 and NLS versus $\Delta$ NLS cells) was significantly decreased (Figure 4f). Moreover, these 3D reconstructions strongly indicated that the low $\beta$-tubulin intensities were derived from lesser populations of polar MTs, as the spindle geometry was dramatically different, featuring large hollows by the equator and chromosomes forming queues on some prominent thick MT formations (Figure 4, yellow arrows). For quantification of chromosome congression, we counted spindles with lengths of $\bar{x} \pm \mathrm{SE}$, relatively horizontal positions, and well formed metaphase disks (e.g., Figure $4 c$, spindle i), and found that more than $54 \%$ of cells had unaligned chromosomes (e.g., Figure 4c, white arrow), a statistically significant difference of over 4-fold as compared to control and NLS-SF268 cells (Figure 4g). These congression abnormalities, greater than those observed with ablation of all NF1 transcripts [18], occurred within days of exposure to doxycycline, and thus expression of the NLS-NF1 targeting shRNAs and knockdown of NLS transcripts and neurofibromin isoforms. Instantly noticeable was also the lack of astral MTs in all $\triangle$ NLS-SF268 cells (asterisks in Figure 4a and b versus c). All effects were reversed 10 days after removal of doxycycline from the culture medium. These results establish for the first time that NLS- and $\triangle$ NLS-neurofibromins actively participate in the formation of mitotic asters and spindles, possibly by exerting opposing effects, at least as the effects on the spindle length may indicate. Nonetheless, these data suggested that NLS neurofibromins are required for proper spindle assembly and chromosome congression, while pointing out that astral MT formation could be the earliest event to be compromised. 
3.3. Neurofibromin NLS and $\triangle N L S$ Isoforms Differentially Regulate Aster Growth, Astral Microtubule Length, and Spindle Positioning

We have previously demonstrated that endogenous neurofibromin localizes at the duplicated centrosome and co-immunoprecipitates with $\gamma$-tubulin, at least through its GRD and CTD domains, in astrocytes and glioblastoma cells $[18,34]$. Therefore, to address the role of neurofibromin isoforms in mitotic aster formation, we began our investigations with analysis of centrosomal features, during the transition from late $\mathrm{S}$ to $\mathrm{M}$ phases. Survey of cells at late $\mathrm{S}$ to late $\mathrm{G} 2$ and selection of cells with condensed chromosomes (early prophase) with IMARIS intensity analysis showed a statistically significant increase in the volume, as judged by $\gamma$-tubulin immunopositivity, of duplicated centrosomes in cells expressing $\triangle$ NLS neurofibromin, when compared to parental and NLS-SF268 cells (Table 2 and Figure 5, long white arrows in a and c versus b); abundance of $\gamma$-tubulin (not shown) and intensities (Table 2) were similar among all cell lines.

In terms of colocalization levels of NLS or $\triangle$ NLS neurofibromins with $\gamma$-tubulin on the duplicated centrosome, before (e.g., Figure 5, short arrows) or after centrosome separation (Figure 5, long white arrows), lesser amounts of NLS neurofibromin were recorded to associate with $\gamma$-tubulin as compared to $\triangle$ NLS neurofibromin (Table 2). Close inspection of the separated centrosomes in confocal images showed that, in NLS-SF268 cells and in parental cells, the neurofibromin-positive areas partially overlapped with those positive for $\gamma$-tubulin, whereas in $\Delta$ NLS cells, the $\gamma$-tubulin area was visibly larger (Figure 5, yellow arrows and small panels). While it is not possible at this level of analysis to interpret these patterns, in conjunction with the metaphase phenotypes (Figure 4), these data altogether indicated that potentially NLS neurofibromins contribute to the formation of a more efficient mitotic centrosome, in terms of future spindle assembly and function.

We next sought to investigate whether the effects on centrosomes, imposed by the presence or absence of an NLS in the sequence of neurofibromin, also affected formation of mitotic asters, by co-immunostaining cells synchronized at prophase with $\beta$-tubulin and neurofibromin (Figure 6 ). More specifically, in parental SF268 glioblastoma cells and in cells expressing NLS-neurofibromin, asters clearly bore MTs extending towards the cell cortex (astral MTs) and inwards (polar, interpolar MTs), while in cells lacking NLS neurofibromin projections to the cortex were absent (Figure 6 left column, $a$ and $c$ versus b). This is best appreciated when only the one plane (of $0.34 \mu \mathrm{m}$, the limit of confocal imaging resolution for the 63x lens we used) that contained the maximum signal of $\beta$-tubulin is viewed (Figure 6, all middle and right columns of panels) and the prominently tangent projections of astral MTs become apparent in both parental and NLS-SF268 cells, as well as the almost complete loss of such astral MTs in $\triangle$ NLS-SF268 (Figure 6, a and c versus b).

Using the ImageJ plugin Single Neurite Tracer within an area defined as the outside half of a circle centered on a centrosome, the length of all visible microtubules that contacted the cortex was quantified in cells at metaphase. As expected from the spindles imaging (Figure 4 and Supplementary Figure S4), the clearly visible tuft of microtubules in SF268 had an average length of $4.0 \pm 0.19 \mu \mathrm{m}$ (Figure $6 \mathrm{~d}$ ), elongated astral MTs with an average length of $5.9 \pm 0.33 \mu \mathrm{m}$ were steadily recorded for cells expressing NLS-neurofibromin (Figure $6 \mathrm{~d}$ ), and a robust loss in cells expressing $\triangle$ NLS neurofibromin was established (Supplementary Figure S4c, versus a and b), with a mere 5\% of cells possessing only a few, short astral MTs if any (Figure 6d). Although incompletely understood, proper astral formation is required for spindle position and aberrations of astral MTs correlate well with spindle misorientation (e.g., [4]). Consequently, the abnormal patterns of astral MT projections with loss of NLS-neurofibromin led us to examine whether spindle positioning was also affected. Indeed, loss of astral MTs along with loss of NLS-neurofibromin led to differential positioning of the usually parallel to the growing cell surface spindle by several degrees (Figure 6e). 
(a)

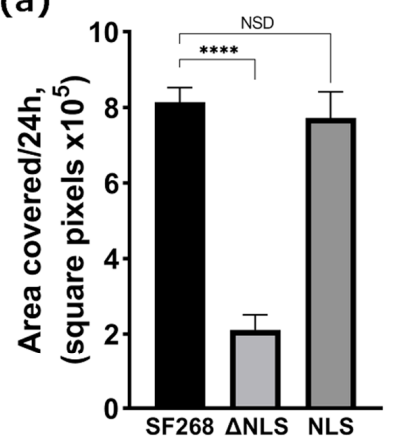

(b) SF268
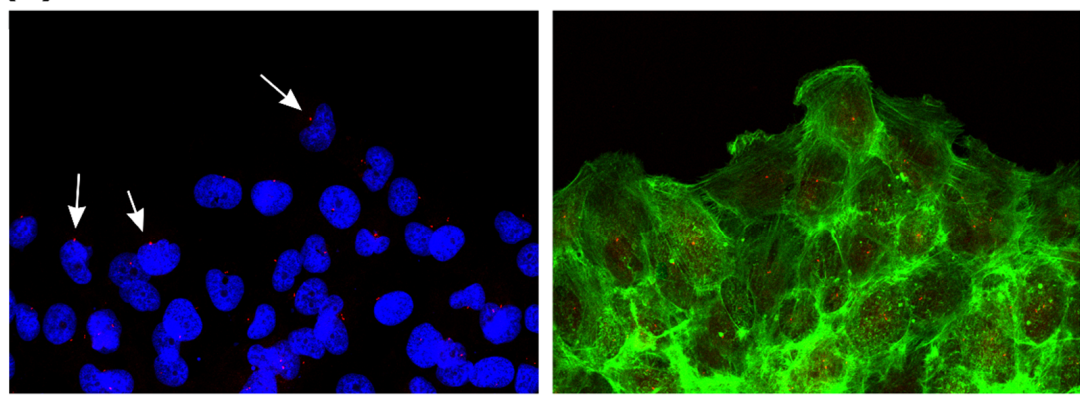

(c) $\Delta$ NLS-SF268
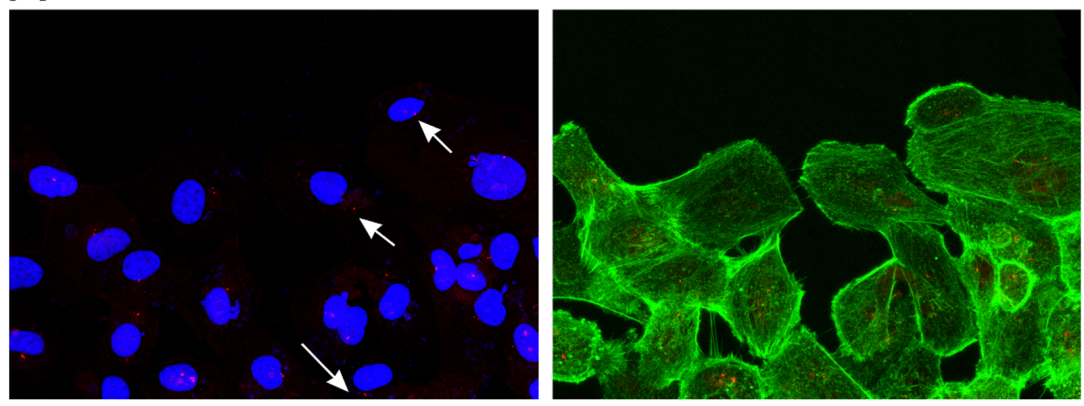

\section{(d) NLS-SF268}

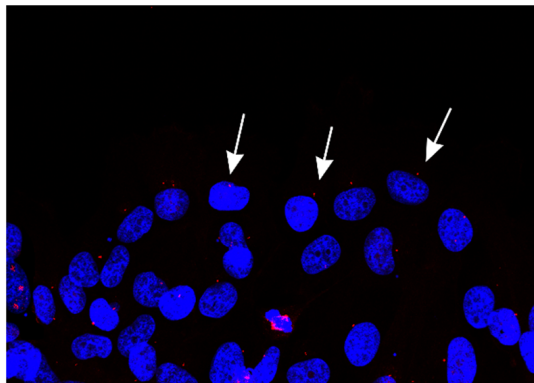

Y-Tubulin/Hoechst

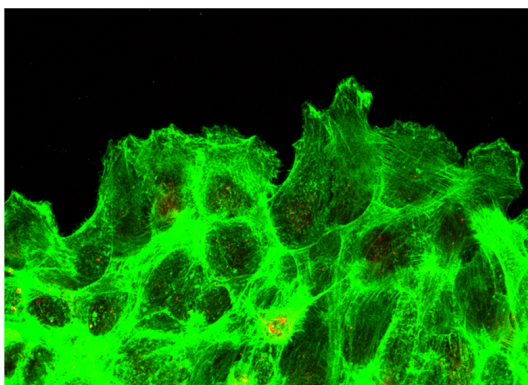

Y-Tubulin/F-actin

Figure 3. Knockdown of NLS neurofibromin imposes changes in orientation of MTOCs and migration patterns of glioblastoma cells. (a) Quantification of the wound healing assay at $24 \mathrm{~h}$. The wound area was calculated by manually tracing in captured images at 0 and $24 \mathrm{~h}$ post-scratching and data were analyzed by ANOVA and Tukey post hoc test. Bracketed bars represent the mean and standard error of five different experiments per cell line; ${ }^{* * *}, p<0.0001$, NSD, no significant difference. Comparisons of centrosome position (arrows) in fixed (DSP + PFA), immunostained with $\gamma$-tubulin, (b) parental SF268, (c) $\triangle$ NLS-SF268, and (d) NLS-SF268 cells revealed misorientiation of both centrosomes and leading edges, relative to the nucleus (chromatin stained with Hoechst) and the long axis of the wound (upper part of panels), with loss of NLS neurofibromins. Images are the maximal intensity projection of confocal serial $0.34 \mu \mathrm{m}$-thick Z-sections with $\gamma$-tubulin and Hoechst signals $(\sim 10 \mu \mathrm{m})$. 
(a) SF268
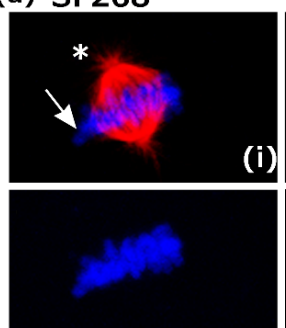

\section{(1)}

\section{(c) $\Delta$ NLS-SF268}
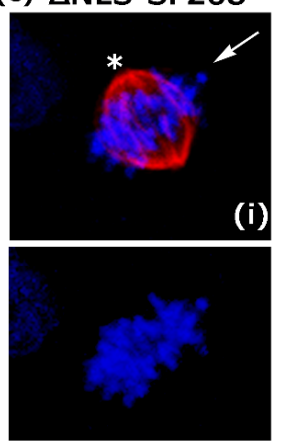

(d) 3D RECONSTRUCTION
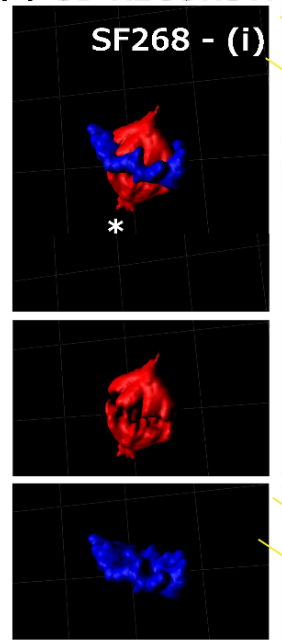

(e)

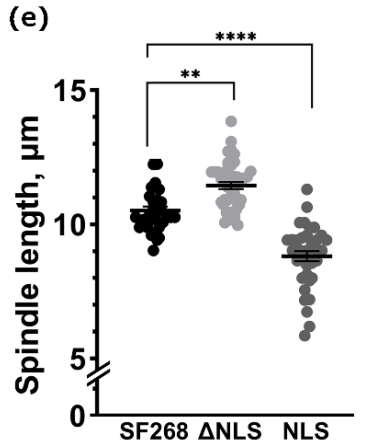

(f) (b) NLS-SF268
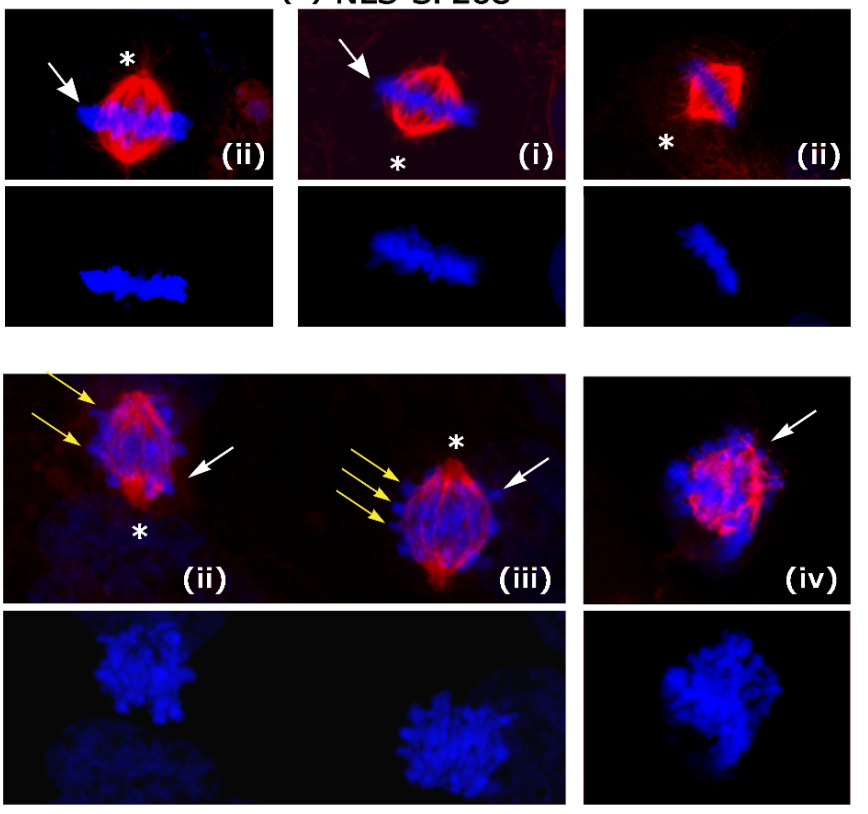

$\beta$-Tubulin Hoechst

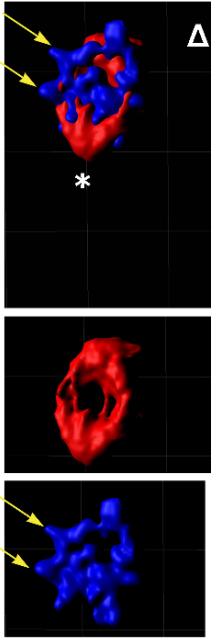

$\Delta N L S$ (ii) and (iii)
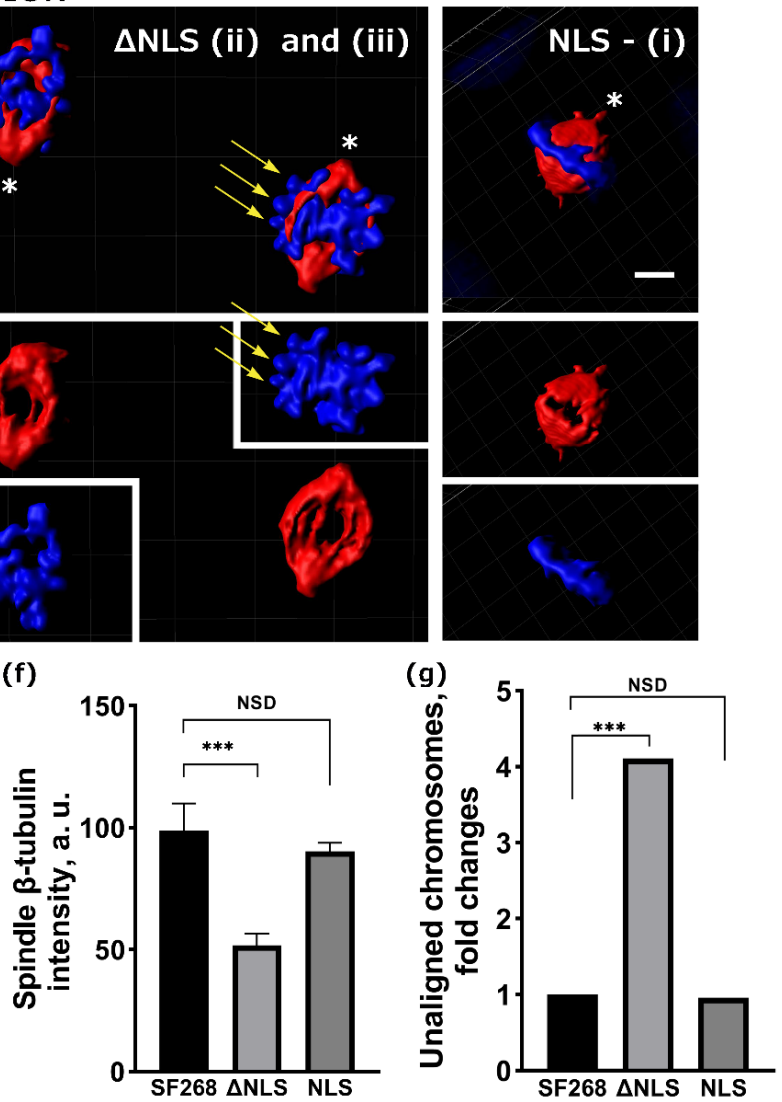

Figure 4. Spindle MT properties and configuration, and chromosome congression are regulated by NLS neurofibromin isoforms. Immunofluorescence confocal images of synchronized cells in metaphase treated with DSP and stained for $\beta$-tubulin (red) and chromatin (blue) of (a) SF268, (b) NLS, and (c) $\triangle$ NLS-SF268 cells. SF268 parentals and NLS-SF268 cells have astral MTs emanating from the spindle poles (asterisks) and proper chromosome congression at the spindle equator (white arrows). $\Delta$ NLS cells lack astral MTs (asterisks) and display abnormal chromosome congression (yellow arrows); Latin numerals in panels label individual spindles. (d) 3D reconstructed confocal images of metaphasic cells, using IMARIS. Yellow arrows show abnormal chromosome congression and asterisks astral MTs 
(Latin numbers indicate identical spindles shown in a-c). Bar $=5 \mu \mathrm{m}$ in all panels. (e) Quantification of spindle length in each genetic background, measured as maximal pole-to-pole distance and (f) of $\beta$-Tubulin intensities in spindles, measured using IMARIS; bracketed bars represent the means and standard errors of measurements of 30-40 spindles per cell line from each of 3 separate experiments. (g) Percentage of spindles in metaphase with aberrant chromosome congression, expressed as fold change over parentals, calculated from a 200 metaphases per cell line from each of 3 different experiments. $p$ values for all graphs, based on $\bar{x} \pm \mathrm{SE}$ are: ${ }^{* *} \leq 0.01,{ }^{* * *} \leq 0.001,^{* * * *}<0.0001$, and NSD, no significant difference in ANOVA (see also Supplementary Figure S4).

Table 2. Quantitative intensity of $\gamma$-tubulin and neurofibromin isoform colocalization analysis in cells modified for expression of NF1 transcripts.

\begin{tabular}{lccc}
\hline & \multicolumn{3}{c}{ Centrosome } \\
\cline { 2 - 4 } & $\gamma$-Tubulin Volume, $\mu \mathbf{m}^{3}$ & $\gamma$-Tubulin Intensity & $\begin{array}{c}\text { Colocalization, } \gamma \text {-Tubulin and } \\
\text { Neurofibromin }\end{array}$ \\
\hline SF268 & $2.85 \pm 0.14$ & $58.7 \pm 4.61$ & $0.68 \pm 0.02$ \\
$\Delta$ NLS-SF268 & $5.35 \pm 0.31^{* *} \uparrow$ & $67.5 \pm 2.93+$ & $0.62 \pm 0.03 \dagger$ \\
NLS-SF268 & $2.87 \pm 0.39+$ & $62.6 \pm 0.88+$ & $0.48 \pm 0.06^{* *} \downarrow$ \\
\hline
\end{tabular}

Colocalization analysis using Volocity ${ }^{\circledR}$ and Pearson's correlation coefficient (PCC) of $\gamma$-tubulin and neurofibromin. IMARIS software was used to calculate the centrosome volume and the intensity of $\gamma$-tubulin. Numerical values represent the mean \pm SE in arbitrary units and $p$ values refer to the statistical differences from comparisons between each genetically modified cell line and the parental SF268 cells (20 cells per cell line from each of the 5 experiments); arrows indicate the direction of these differences; $* *, p<0.01 ;+$, no significant difference.

\section{(a) SF268}
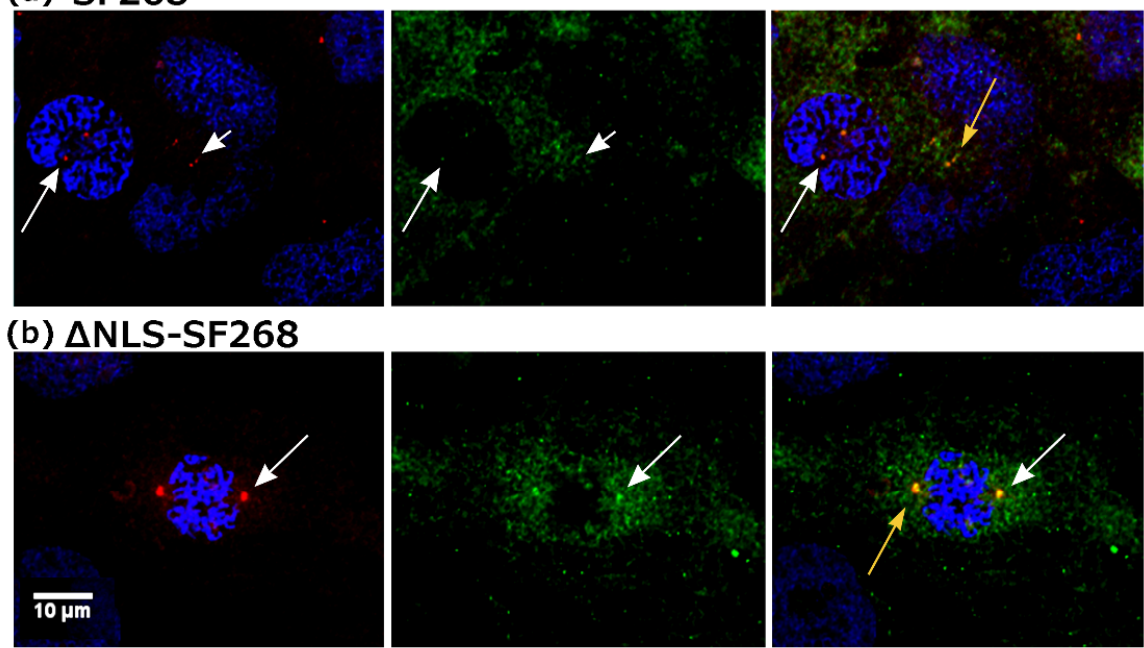

\section{(c) NLS-SF268}

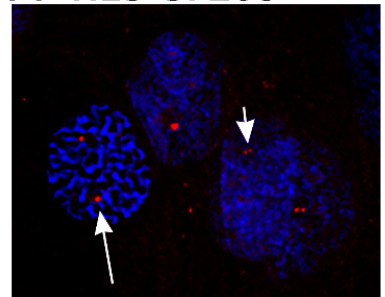

Y-Tubulin Hoechst

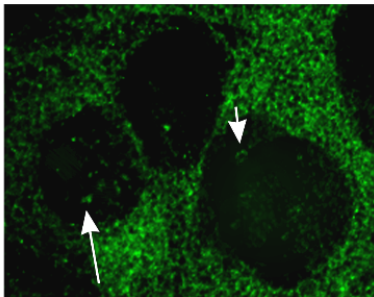

Neurofibromin

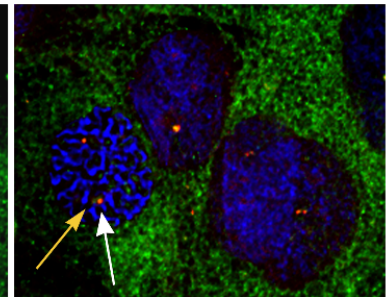

Merge

Figure 5. Differential neurofibromin isoform colocalization with $\gamma$-tubulin on mitotic centrosomes. (a) SF268, (b), $\triangle$ NLS and (c) NLS synchronized late S-G2 cells were fixed with PFA and immunostained with $\gamma$-tubulin (red) and neurofibromin (green); chromatin was stained with Hoechst (blue). Panels, 
representing maximal intensity projections of all stacks containing fluorescence signals, show colocalization of $\gamma$-tubulin and neurofibromin (long white and short arrows). Partial overlapping signals in parental SF268 and in NLS-SF268 cells, but not $\Delta$ NLS-SF268 cells are denoted with yellow arrows; the same centrosomes are shown at $300 \%$ magnification in the neighboring small panels.

Abnormal positioning of the spindle typically associates with altered times spent at mitotic stages [6,71]. Thus, flow cytometry results showed that NLS transcript knockdown significantly increased the percentages of cells in G2/M phase: $15.2 \%$ with $\Delta$ NLS-expression, compared to $10.6 \%$ in parental and $9.8 \%$ with NLS-expression, while doubling time analysis showed that the $38 \mathrm{~h}$ cell cycle of parental SF268 (G1: $17.1 \mathrm{~h}, \mathrm{~S} 10.3 \mathrm{~h}, \mathrm{G} 26.8 \mathrm{~h}, \mathrm{M} 3.8 \mathrm{~h}$ [18]) was now extended to $40.2 \mathrm{~h}$ in cells lacking NLS isoforms, but not affected in cells lacking $\triangle$ NLS neurofibromin (Supplementary Figure S5). Quantification of the mitotic stage distribution for each cell type revealed that loss of NLS-neurofibromin elicited a great increase in cells in metaphase (Figure 6f). Because of the aster formation abnormalities in $\triangle$ NLS cells (Figure 4), we scored cells with full length spindles and MTs curved towards the equator as metaphasic, and, as a result, negligible percentages were recorded for prometaphasic $\triangle$ NLS cells. The high percentage of metaphasic $\triangle$ NLS cells most likely reflected longer time spent at metaphase and correlates well with the increase in the overall duration of the cell cycle. In contrast, NLS cells had significantly lower percentages in pro- and metaphase over parentals, which, combined with higher percentages in cytokinesis, reflected an overall acceleration through metaphase. Considered together, these results document for the first time that neurofibromin actively participates in the formation of mitotic asters and the progression of mitosis. Moreover, these data further support the notion that NLS- and $\triangle$ NLS-neurofibromins may exert opposing effects during aster formation and spindle assembly, as, in parental cells, these two parameters appear to be the arithmetic sum of the results obtained with each isoform type.

\subsection{Chromosome Segregation Fidelity Requires NLS-Neurofibromin Expression}

The metaphase phenotypes along with the anaphase time variability, observed with expression of $\triangle$ NLS-neurofibromins only, led us to investigate next chromosome segregation events during anaphase and telophase in fixed cells (Figure $7 \mathrm{a}-\mathrm{c}$ ). We found that, in parental and NLS-neurofibromin expressing cells, chromosomes appeared to move in a coordinated manner towards the opposed poles, while chromosome compaction was readily seen (Figure 7a,c, arrows). In cells expressing only $\triangle$ NLS-neurofibromins, these parameters were again inversely regulated, that is, despite the prolonged time spent at metaphase, there was a significant increase in cells with chromosome segregation errors $(>40 \%)$, mainly lagging chromosomes (Figure 7 , arrows in b.i and ii), and occasionally chromosome bridges, without much obvious compaction of the main chromosome mass. Similar delays in chromosome compaction in cells lacking NLS-neurofibromin were observed in telophase (e.g., Figure 7, arrows in b.iii). Tracking the effects of the described aster and spindle assembly perturbations, and of the chromosome segregation errors in similarly stained cells, we found that the missegregated chromosomes resulted in a high frequency of micronuclei formation, that is an almost 5 -fold increase in the numbers of cells containing micronuclei within in 2 passages (P2) or $\sim 10$ mitotic cycles (Figure $7 \mathrm{~d}$ and Supplementary Figure S6a-c). Taken together, these results strongly suggest that neurofibromin isoforms, changed only by the inclusion, or not, of an NLS sequence have opposing, possibly complementary when both expressed, functions, that are required for mitotic aster formation and spindle assembly for efficient chromosome congression and error correction, at least in an astrocytic cellular background. 
(a) SF268
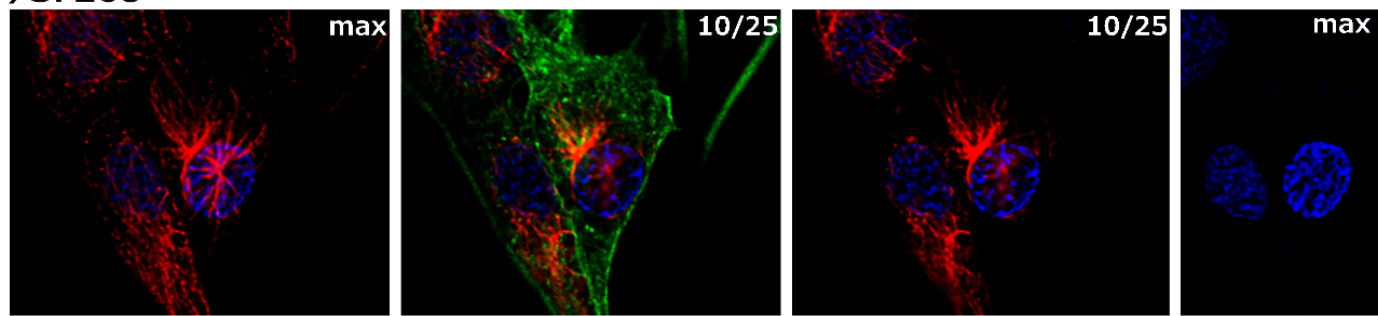

\section{(b) $\Delta$ NLS-SF268}
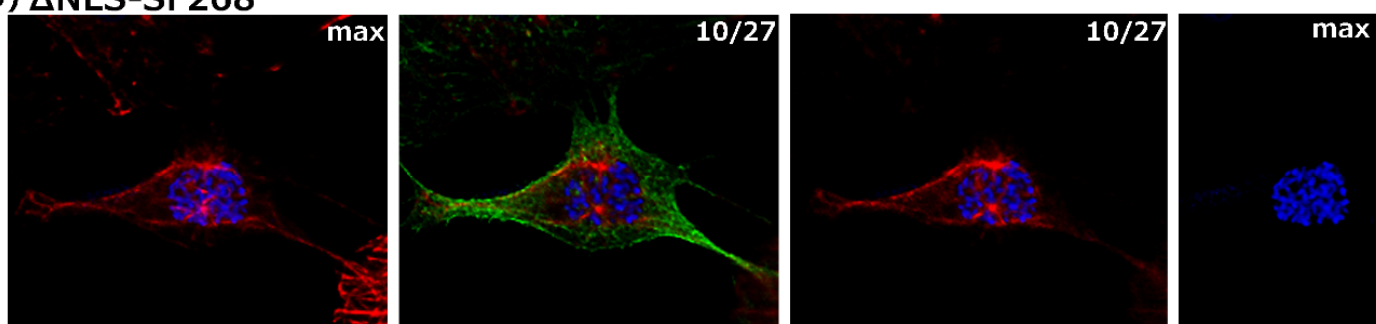

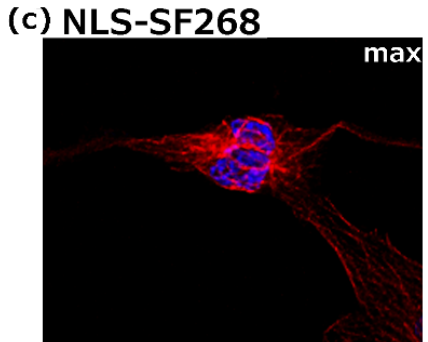

B-Tubulin Hoechst

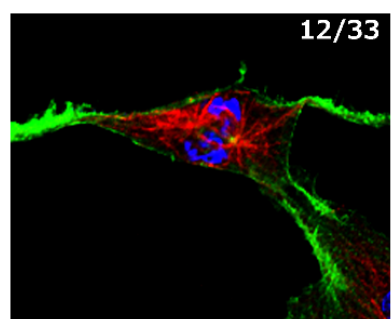

F-actin

B-Tubulin Hoechst

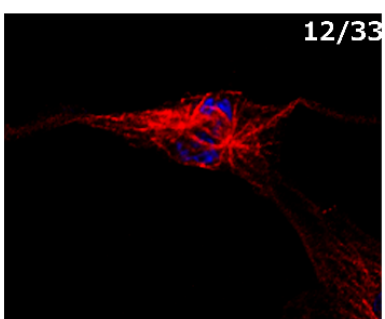

B-Tubulin Hoechst

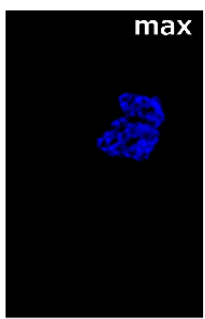

Hoechst (d)

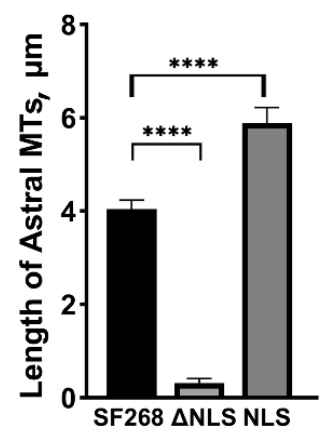

(e)

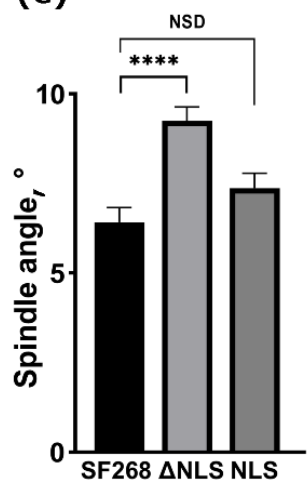

(f)

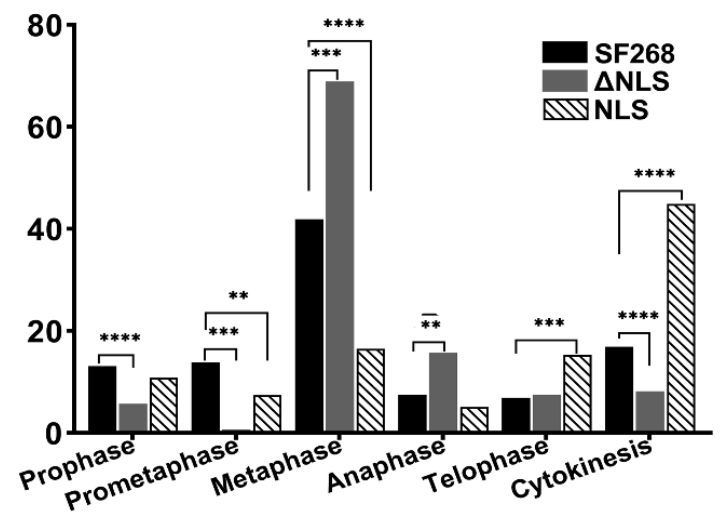

Figure 6. Aster formation is drastically and inversely regulated by NLS and $\triangle$ NLS neurofibromin isoforms. Synchronized cells were fixed with PFA, immunostained for $\beta$-tubulin (red) and co-stained with Hoechst for chromatin (blue) and with phalloidin for F-actin (green) visualization. Prophase images of (a) parental, (b) $\triangle$ NLS and (c) NLS SF268 cells were captured as confocal Z-sections of $0.34 \mu \mathrm{m}$ steps. Left column of panels contains compilations of all Z-sections containing $\beta$-tubulin and chromatin signals (maximal intensity projection), i.e., a z-stack of $8.5 \mu \mathrm{m}, 9.18 \mu \mathrm{m}$, and $11.22 \mu \mathrm{m}$, for a, $\mathrm{b}$, and c respectively. Middle columns contain single sections at 3.40, 3.40, 4.08 $\mu \mathrm{m}$ from the growing surface, corresponding to the indicated section number (over total sections), with (middle column) or without (right column) the co-projection of F-actin optical signals. Right panels are the maximal intensity projection of Hoechst staining. Quantifications of (d) astral length, (e) spindle angle, and 
(f) mitotic stage percentages. Bracketed bars in d and e represent the means and standard errors of measurements in 25-30 cells per cell line from each of 3 separate experiments with synchronized cells and in $\mathrm{f}$, mitotic stage distribution of asynchronous cells $(n=800$ mitotic figures for each cell line from five different experiments). $p$ values, based on $\bar{x} \pm \mathrm{SE}$, are: ${ }^{* *} \leq 0.01,{ }^{* * *} \leq 0.001,{ }^{* * * *} \leq 0.0001$; NSD, no significant difference.

\section{(a) SF268}
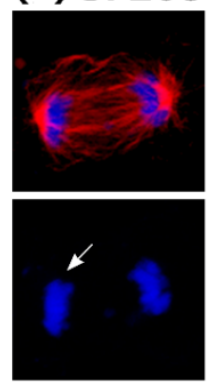

(b) $\triangle$ NLS-SF268
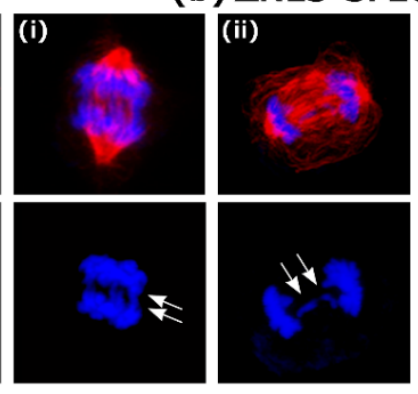

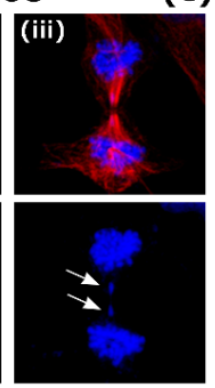

(c) NLS-SF268
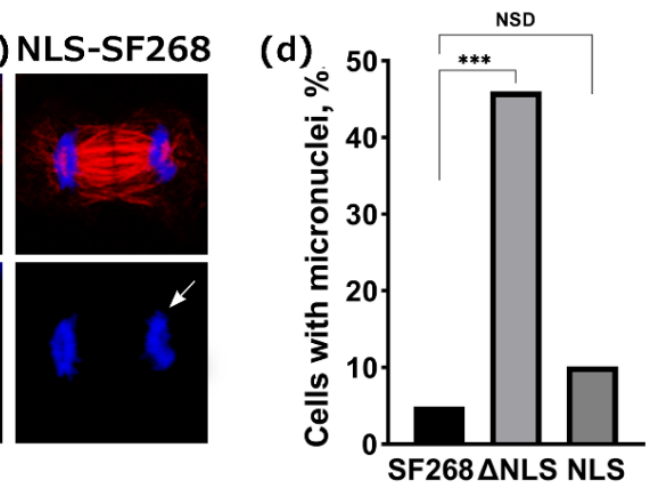

Figure 7. NLS-Neurofibromin is required for accurate chromosome segregation. Immunofluorescence confocal images of (a) SF268, (b) $\Delta$ NLS-SF268, and (c) NLS-268 synchronized cells, treated with DSP prior to fixation and stained for $\beta$-tubulin (red) and chromatin (blue). SF268 and NLS-SF268 spindles show proper chromosome segregation during late anaphase, whereas the anastral $\Delta$ NLS spindles in anaphase (i, early and ii, late) and cytokinesis (iii) show high frequency of segregation errors, highlighted by arrows. (d) Quantification of micronuclei, as described in Supplementary Figure S6, shows high frequency of micronuclei occurrence in $\triangle$ NLS- but not in NLS-SF268 cells. Bars are the percentage of cells with micronuclei from an $n \geq 500$ from 3 different experiments and $p$ value, based on $\bar{x} \pm \mathrm{SE}$ is: ${ }^{* * *} \leq 0.001$; NSD, no significant difference.

\section{Discussion}

When we previously probed the nuclear functions of the tumor suppressor neurofibromin, we found that it actively accumulates, in a Ran-dependent manner, in the nucleus prior to mitosis to participate in proper chromosome congression [18], as do many other tumor suppressors (e.g., [14-17,19-21,72]). We now further elaborate on these findings with experimental evidence that supports a direct function of neurofibromin in mitotic aster and spindle assembly for proper chromosome congression and faithful genomic transmission.

Unsurprisingly for such a large gene and protein, functional neurofibromin isoforms have been reported, which are produced by alternative exon splicing in a cell type-specific mode. Splicing of exon 31, which generates neurofibromins with different RasGAP activities has been previously addressed [34,45], whereas the importance of the inclusion of the C-terminus NLS-bearing exon 51 [52] has not been previously explored. By using stable transfections with lentiviruses carrying shRNAs that specifically knockdown NLS- or $\triangle$ NLS-NF1 transcripts in the human glioblastoma cell line SF268, we were able to produce glioblastoma cellular backgrounds that conditionally express either NLS- or $\triangle$ NLS-NF1 transcripts (Supplementary Figure S1). In this manner, we were able to dissect the roles of NLS or $\triangle$ NLS neurofibromins, which differ in the inclusion of the corresponding to exon 51 sequence of 41 amino acids and the expression of a bipartite NLS sequence (Scheme 1).

Lack of nuclear neurofibromin immunoreactivity in the $\Delta$ NLS-SF268 cells (Figure 1 and Table 1 ) triangulates our previous results with Ran variants overexpression and nuclear subfractionation approaches, and further establishes that this large protein may only enter the nucleus through the Ran/importin system, that is only through its NLS [18,48]. A second requirement for its cell-cycle regulated nuclear entry is phosphorylation by Protein Kinase C (PKC) on serine 2808, a residue relatively close to the NLS (Scheme 1). This residue is retained in both isoforms, yet in silico analysis shows that three other potential phosphorylation sites within the 41 amino acid sequence encoded by exon 51 are lost in $\triangle$ NLS neurofibromins, namely a PKC site on T2519, a tyrosine kinase site on Y2556, 
and a site for Casein kinase 2 (CK2) on T2554. These phosphorylations may also play roles in the nuclear import of NLS neurofibromins in preparation of mitosis, especially the CK2 site, as this significant for cell cycle progression kinase [73] phosphorylates the yeast neurofibromin homologue Ira2 to prevent its degradation [74]. Considered together, our findings further establish the nuclear import of NLS neurofibromins and exclusion of $\triangle$ NLS ones; however, whether one functions dominantly over the other in the cytosolic area or after nuclear envelope breakdown is not directly addressed.

Unlike results with Western blotting, in immunoprecipitations with three antibodies against the $\mathrm{N}$-terminus, different amounts of endogenously expressed neurofibromin were recovered from $\triangle \mathrm{NLS}$ or NLS-SF268 cell lysates (Supplementary Figure S1). Because protein conformation in cell lysates differs and may closer resemble endogenous states than those attained after fixation or exposure to SDS, we reasonably presume that inclusion, or not, of the 41 amino acids of exon 51 may indeed alter the conformation of the molecule. With an estimated molecular mass of $\sim 320 \mathrm{kDa}$, neurofibromin has been repeatedly shown to migrate as a $220-250 \mathrm{kDa}$ protein in SDS polyacrylamide gels [32,48,49,59,60,75], most likely due to the known intramolecular interactions between its domains and specific protein folding. At any case, the expected differential conformation of the $\triangle$ NLS or NLS neurofibromins would also impact its well established intermolecular interactions $[18,35,60,75]$. In support of this argument, colocalization with F-actin [18,51], an interaction carried out by the further upstream CSRD domain in the N-terminus [47,49], was differential for the two isoforms (Figure 1 and Table 1). Moreover, colocalization analyses with $\beta$ - and $\gamma$-tubulins showed that both NLS and $\Delta$ NLS neurofibromin isoforms retain the ability to bind tubulins, although the affinity of NLS is higher for $\beta$ - and lower for $\gamma$-tubulin when compared to $\Delta$ NLS (e.g., Figure 1; Tables 1 and 2).

These differential effects of each neurofibromin type, collectively the effects on cytosolic MT intersection occurrence (Figure 2) and cytosolic or spindle $\beta$-tubulin polymer regulation (Table 1 and Figure 4e), strongly support the previously suggested role of neurofibromin as a MAP. Experimentally, at least three neurofibromin domains have been previously identified to bind tubulins, namely GRD, SEC14, and CTD. Affinities to tubulin for the first two domains were explored for regulation of neurofibromin's RasGAP activity $[33,34,36]$ and the third for baiting neurofibromin associated proteins [35] or for nuclear import studies [18]. More specifically for CTD, high affinity to GFP-CTD (+NLS) was identified for $\alpha-, \beta$ - and $\gamma$-tubulins [18], as well as for the Collapsin response mediator protein 2 (CRPM2) [35], a plus-end MAP [76] thoroughly studied for its abilities to promote MT assembly during neuronal axon formation and to endorse actin filament stability at growth cones [77]. Interestingly, CRPM2 also decorates the mitotic spindle and midzone structures, while its depletion leads to altered spindle position, destabilized astral MTs, and segregation errors [78]. Thus, we performed sequence comparisons (EMBOSS Water), which showed a 50\% identity/similarity of the MAP domain of CRMP2 [78] with neurofibromin residues 1815-1839 (Supplementary Figure S7). At higher percentages of similarity, we found three additional small Tau-like motifs [79] containing the critical lysine for $\alpha$-tubulin binding (Supplementary Figure S7), one of which corresponds to codons apposed to exons 50-51 or 50-52 junctions and are thus mostly likely to be affected.

Moreover, the direction of the $\triangle$ NLS or NLS knockdown effects was most often opposite, suggesting that the two possibly interact when both present in wild type cells. Indeed, neurofibromin has been shown recently to dimerize and affinity precipitation experiments have pinpointed CTD as the likely mediator [48]; whether this analysis included NLS or $\triangle$ NLS variants was not, however, disclosed. At any rate, the interesting question remains, if loss of the amino acids encoded by exon 51 , suffice to produce a different MAP. Numerous examples exist where one to few amino acids may change the functional properties of a protein, by imposing changes on protein conformation and/or sites for post-translational modifications, and our data, starting with the immunodetection experiments, suggest that this is the case for the $\triangle \mathrm{NLS}$ and NLS isoforms. By the same token, the expression of two closely related isoforms yet with differential effects on MT structures further suggests that an extra layer of regulation on MT dynamics is thereby served. 
The differential properties of the NLS and $\triangle$ NLS isoforms are further highlighted by the effects on centrosome size, as assessed by their $\gamma$-tubulin immunopositive volume (Table 2 and Figure 5), and on MT nucleation prior to nuclear envelope breakdown, when the relatively sparse microtubule formations of interphase cells transfigure into a bipolar spindle. In certain species, cell types, or experimental set-ups that exemplify non-centrosomal MT nucleation, spindles are formed and mitoses are completed [80,81]. Yet, in most animal cells, the centrosome is the major MTOC for spindle MT assembly and duplicated centrosomes serve as poles for already nucleated astral MTs that radiate towards and interact with a core machinery, anchored on the cell cortex, to orient the spindle. Furthermore, astral poles nucleate highly dynamic MTs from the spindle [82], K-fibers from kinetochores [7,31,83], and interpolar bundles that elongate the spindle [4-6]. A large body of literature has postulated that $\gamma$-tubulin and its several associated proteins in higher eukaryotes form a large ring complex $(\gamma-\mathrm{TuRC})$ that serves as the major template for $\alpha$-tubulin subunits of MT minus ends [84]. Still, the control of MT nucleation remains incompletely understood, for example $\gamma$-TuRC [85] is dispensable for this purpose (e.g., [86]). This, in turn, underscores the role of MAP-dependent regulation of nucleation, which may increase, as does XMAP125 [87] often in synergy with structurally unrelated MAPs [88], or inhibit nucleation from centrosomes, as does stathmin [89]. While we may only speculate on how nucleation at the duplicated, larger centrosomes (Figure 5) appeared to be prevented for MTs radiating to the cell cortex, yet allowed for those from the chromosome area when only $\triangle$ NLS neurofibromins are expressed (Figure 6), it is feasible that $\triangle$ NLS neurofibromins may impede partitioning of tubulins from polymer to soluble dimer pools at mitotic entry [90], in a manner similar to the temporal mode of action of stathmin [89]. Another possibility is that the decreased affinity of $\triangle$ NLS neurofibromins to actin (Figure 1 and Table 1) may interfere with interactions of actin and MTs, as also demonstrated by the aberrant pattern of cell migration (Figure 3, Supplementary Figure S3, and Supplementary Videos S1-3). Indeed, actin and MT interactions at the nuclear envelope during G2 may have significant impact on centrosome positioning for cell division and spindle orientation [91,92]. Lastly, we may not exclude the possibility, which has yet to be addressed, that the RasGAP activities of NLS and $\triangle$ NLS isoforms vary and thus different transcriptional regulation on MT nucleation regulators is exerted via Ras-dependent pathways.

Astral, $\gamma$-TuRC nucleated MTs are essential for proper anchoring to the cell cortex and correct mitotic spindle orientation, a fundamental process in embryo development and in tissue renewal [93]. Appropriately, a number of diverse families of proteins across species have been shown to impact the timely assembly and dynamic maintenance of astral MTs, mostly through depletion studies. Among those, few studies record shorter or weaker astral MTs, while the astral loss, to the extend we report here with NLS-neurofibromin depletion and expression of only $\triangle$ NLS isoforms (Figures 4 and 6), has not been reported. The closest parallelism to the effects of NLS-neurofibromin knockdown, namely increased cytosolic tubulin polymer (Table 1) with fewer MT intersections (Figure 2), loss of astral MTs, delay at metaphase and abnormal chromosome congression (Figures 4 and 6), and finally abnormal chromosome segregation and increased micronuclei frequency (Figure 7), is with ablation of EB2, an important MT plus-end tracking MAP. Unlike EB1 and EB3, EB2 preferentially binds to microtubule lattices [94], in a phosphorylation-dependent manner to protect MT dynamic instability during mitosis [95]. Ablation of EB2 produces straighter, bundled cytosolic MTs with fewer MT intersection events [96], while its functional ablation (phosphoablating mutants) leads to a marked delay in anaphase onset, and abnormalities in chromosome congression and genomic transmission [95]. Similar depletion phenotypes have suggested that the multidomain, multifunction adaptor proteins ALG-2-interacting protein X (ALIX) [97] and the Receptor of Activated C Kinase 1 (RACK1) [98] are also essential for proper astral MT elongation, spindle orientation and chromosome segregation, acting through regulation of motor protein (RACK1) or other MAPs (ALIX); these possibilities are worth pursuing experimentally for NLS neurofibromin. In contrast, most parameters assessed with $\triangle$ NLS-depletion and expression of NLS neurofibromin diverge only slightly from those registered for the parental SF268 cells, namely longer astral MTs and shorter spindles (Figures 4 and 6). Such mild effects have been reported after silencing motors from the kinesin family of MAPs, specifically MCAK [99] 
and kinesin-8 (Kif18b) [71,100], and were interpreted as evidence for preferential actions on specific MT subpopulations. Overall, the data we obtained, when assessing a number of parameters, point out that the shorter spindles in NLS cells were more efficient than their $\triangle$ NLS counterparts in protecting the genome and ensuring faithful chromosome segregation.

Expression of $\triangle$ NLS neurofibromins did not appear to impede MT nucleation as severely at the centrosome/pole beyond prophase, and we may deduct that mitotic factors, already accumulated in the chromosome area, drastically enhanced nucleation; then kinetochore-derived microtubules interacted laterally with pole microtubules (Figure 6) for kinetochore loading [101]. It is also possible that the augmin-mediated, centrosome-independent nucleation from preexisting MTs within the spindle $[81,102,103]$ was upregulated, if the dramatic spindle geometry of some prominent thick MT formations with queued up chromosomes is to be interpreted (Figure 4). As the spindle equator area was the most devoid of tubulin signals, we may assume that non kinetochore, bridging MTs [104] were also sparse and late to develop. The patterns we observed strongly resemble the "prometaphase ring or belt" in the human diploid cell line RPE1, caused by unstable lateral interactions between kinetochores and microtubules that dominate early prometaphase [70]. Computational modeling predicts that such a toroidal distribution would enhance exposure of kinetochores to a high density of MTs and facilitate amphitelic attachments [70]. As we very rarely, $<0.01 \%$, observed this configuration in parental or NLS-SF268 cells, we assume that they must execute chromosome prepositioning extremely fast, whereas $\triangle N L S$ cells were arrested at this stage for a long time, or till most defects in spindle assembly were corrected and stable end-on attachments became possible. Indeed, cells were able to undergo mitosis, and segregation abnormalities, mostly lagging or unattached chromosomes (Figure 7) at anaphase, were less drastic than those expected from the dramatic spindle and chromosome congression geometries. Despite, however, this remarkable correction, the frequency of micronuclei was significantly increased (Figure 7 and Supplementary Figure S6). Moreover, this defect accounted as the only irreversible event upon doxycycline removal. Observed at elevated frequencies in cancer cell lines, micronuclei frequency is a predictive biomarker for genetic instability and for rapid karyotype evolution [105], as their few chromosomes, unprotected from DNA damage, may undergo chromothripsis and chromoanasynthesis [106] and then get incorporated into the genome of the host cell within just 1-2 mitoses [107].

Summarizing, our studies strongly demonstrate that inclusion, or not, of the amino acids encoded by exon 51 may alter the presentation of neurofibromin's microtubule-binding domains, which, in conjunction with the ability or not to enter the nucleus at late $S$, may explain the role of the molecule in spindle assembly and chromosome segregation. Finally, when the observed phenotypes are considered together, our hypothesis that NLS and $\triangle$ NLS neurofibromin isoforms may balance each other out for the regulation of astral MT and spindle dynamics is further strengthened.

Supplementary Materials: The following are available online at http://www.mdpi.com/2073-4409/9/11/2348/s1, Figure S1: Validation of knockdown efficiency using shRNAs against $\triangle$ NLS- and NLS-NF1 mRNA transcripts by qPCR and Western Blotting, Figure S2: Single planes of $\beta$-tubulin or F-actin co-localization with neurofibromin, Figure S3: Wound healing assay, Figure S4: Astral MT networks after fluorescence signal enhancement, Figure S5: Loss of NLS-neurofibromins elicits increases in the percentage of cells in G2/M phase and in doubling time, Figure S6: Knockdown of NLS neurofibromin elicits high frequency of micronuclei, Figure S7: Tubulin binding motifs of neurofibromin, Video S1: Time-lapse video microscopy of SF268 cells, Video S2: Time-lapse video microscopy of $\Delta$ NLS-SF268 cells, Video S3: Time-lapse video microscopy of NLS-SF268 cells.

Author Contributions: Conceptualization and methodology design, C.P., E.T., D.M.; investigation, C.P., E.T., D.S., K.G., D.M.; image analysis, C.P., formal analysis, C.P., E.T., D.S., K.G., D.M.; resources, D.M.; writing-original draft preparation, D.M., C.P., E.T., D.S., K.G. supervision and funding acquisition, D.M. All authors have read and agreed to the published version of the manuscript."

Funding: This research was partially supported by PENED (grant 03ED778) from the Greek Secretariat for Research and Technology (D.M., E.T.) and Biomedical Research Foundation of the Academy of Athens (BRFAA) internal funds to D.M. and E.T; A. Delis was supported by BIO-IMAGING-GR (MIS 5002755).

Acknowledgments: We would like to acknowledge the staff from the Biological Imaging Unit, BRFAA, especially Anastasios Delis. 
Conflicts of Interest: The authors declare no conflict of interest.

\section{References}

1. Asbury, C.L. Anaphase A: Disassembling Microtubules Move Chromosomes toward Spindle Poles. Biology 2017, 6, 15. [CrossRef] [PubMed]

2. Maiato, H.; Gomes, A.M.; Sousa, F.; Barisic, M. Mechanisms of Chromosome Congression during Mitosis. Biology 2017, 6, 13. [CrossRef] [PubMed]

3. Walczak, C.E.; Cai, S.; Khodjakov, A. Mechanisms of chromosome behaviour during mitosis. Nat. Rev. Mol. Cell Biol. 2010, 11, 91-102. [CrossRef] [PubMed]

4. Di Pietro, F.; Echard, A.; Morin, X. Regulation of mitotic spindle orientation: An integrated view. EMBO Rep. 2016, 17, 1106-1130. [CrossRef] [PubMed]

5. Kiyomitsu, T. Mechanisms of daughter cell-size control during cell division. Trends Cell Biol. 2015, 25, 286-295. [CrossRef]

6. Meraldi, P. Centrosomes in spindle organization and chromosome segregation: A mechanistic view. Chromosome Res. 2016, 24, 19-34. [CrossRef]

7. Maiato, H.; Rieder, C.L.; Khodjakov, A. Kinetochore-driven formation of kinetochore fibers contributes to spindle assembly during animal mitosis. J. Cell Biol. 2004, 167, 831-840. [CrossRef]

8. He, J.; Zhang, Z.; Ouyang, M.; Yang, F.; Hao, H.; Lamb, K.L.; Yang, J.; Yin, Y.; Shen, W.H. PTEN regulates EG5 to control spindle architecture and chromosome congression during mitosis. Nat. Commun. 2016, 7, 12355. [CrossRef]

9. Reed, S.I. Ratchets and clocks: The cell cycle, ubiquitylation and protein turnover. Nat. Rev. Mol Cell Biol 2003, 4, 855-864. [CrossRef]

10. Zhang, J.; Wan, L.; Dai, X.; Sun, Y.; Wei, W. Functional characterization of Anaphase Promoting Complex/Cyclosome (APC/C) E3 ubiquitin ligases in tumorigenesis. Biochim. Biophys. Acta 2014, 1845, 277-293. [CrossRef]

11. Cuijpers, S.A.G.; Vertegaal, A.C.O. Guiding Mitotic Progression by Crosstalk between Post-translational Modifications. Trends Biochem. Sci. 2018, 43, 251-268. [CrossRef] [PubMed]

12. Bhat, K.M.; Setaluri, V. Microtubule-associated proteins as targets in cancer chemotherapy. Clin. Cancer Res. 2007, 13, 2849-2854. [CrossRef] [PubMed]

13. Schroeder, C.; Grell, J.; Hube-Magg, C.; Kluth, M.; Lang, D.; Simon, R.; Hoflmayer, D.; Minner, S.; Burandt, E.; Clauditz, T.S.; et al. Aberrant expression of the microtubule-associated protein tau is an independent prognostic feature in prostate cancer. BMC Cancer 2019, 19, 193. [CrossRef] [PubMed]

14. Kaplan, K.B.; Burds, A.A.; Swedlow, J.R.; Bekir, S.S.; Sorger, P.K.; Nathke, I.S. A role for the Adenomatous Polyposis Coli protein in chromosome segregation. Nat. Cell Biol. 2001, 3, 429-432. [CrossRef] [PubMed]

15. Muranen, T.; Gronholm, M.; Lampin, A.; Lallemand, D.; Zhao, F.; Giovannini, M.; Carpen, O. The tumor suppressor merlin interacts with microtubules and modulates Schwann cell microtubule cytoskeleton. Hum. Mol. Genet. 2007, 16, 1742-1751. [CrossRef] [PubMed]

16. Ban, S.; Shinohara, T.; Hirai, Y.; Moritaku, Y.; Cologne, J.B.; MacPhee, D.G. Chromosomal instability in BRCA1- or BRCA2-defective human cancer cells detected by spontaneous micronucleus assay. Mutat. Res. 2001, 474, 15-23. [CrossRef]

17. Rong, R.; Jin, W.; Zhang, J.; Sheikh, M.S.; Huang, Y. Tumor suppressor RASSF1A is a microtubule-binding protein that stabilizes microtubules and induces G2/M arrest. Oncogene 2004, 23, 8216-8230. [CrossRef] [PubMed]

18. Koliou, X.; Fedonidis, C.; Kalpachidou, T.; Mangoura, D. Nuclear import mechanism of neurofibromin for localization on the spindle and function in chromosome congression. J. Neurochem. 2016, 136, 78-91. [CrossRef]

19. Morris, V.B.; Brammall, J.; Noble, J.; Reddel, R. p53 localizes to the centrosomes and spindles of mitotic cells in the embryonic chick epiblast, human cell lines, and a human primary culture: An immunofluorescence study. Exp. Cell Res. 2000, 256, 122-130. [CrossRef]

20. Yi, Q.; Zhao, X.; Huang, Y.; Ma, T.; Zhang, Y.; Hou, H.; Cooke, H.J.; Yang, D.Q.; Wu, M.; Shi, Q. p53 dependent centrosome clustering prevents multipolar mitosis in tetraploid cells. PLoS ONE 2011, 6, e27304. [CrossRef] 
21. Manning, A.L.; Longworth, M.S.; Dyson, N.J. Loss of pRB causes centromere dysfunction and chromosomal instability. Genes Dev. 2010, 24, 1364-1376. [CrossRef] [PubMed]

22. Thompson, S.L.; Compton, D.A. Proliferation of aneuploid human cells is limited by a p53-dependent mechanism. J. Cell Biol. 2010, 188, 369-381. [CrossRef]

23. Burrell, R.A.; McClelland, S.E.; Endesfelder, D.; Groth, P.; Weller, M.C.; Shaikh, N.; Domingo, E.; Kanu, N.; Dewhurst, S.M.; Gronroos, E.; et al. Replication stress links structural and numerical cancer chromosomal instability. Nature 2013, 494, 492-496. [CrossRef] [PubMed]

24. Gerlinger, M.; Rowan, A.J.; Horswell, S.; Math, M.; Larkin, J.; Endesfelder, D.; Gronroos, E.; Martinez, P.; Matthews, N.; Stewart, A.; et al. Intratumor heterogeneity and branched evolution revealed by multiregion sequencing. N. Engl. J. Med. 2012, 366, 883-892. [CrossRef] [PubMed]

25. Godek, K.M.; Kabeche, L.; Compton, D.A. Regulation of kinetochore-microtubule attachments through homeostatic control during mitosis. Nat. Rev. Mol Cell Biol 2015, 16, 57-64. [CrossRef]

26. Gorgoulis, V.G.; Vassiliou, L.V.; Karakaidos, P.; Zacharatos, P.; Kotsinas, A.; Liloglou, T.; Venere, M.; Ditullio, R.A., Jr.; Kastrinakis, N.G.; Levy, B.; et al. Activation of the DNA damage checkpoint and genomic instability in human precancerous lesions. Nature 2005, 434, 907-913. [CrossRef] [PubMed]

27. Lengauer, C.; Kinzler, K.W.; Vogelstein, B. Genetic instability in colorectal cancers. Nature 1997, 386, 623-627. [CrossRef]

28. Potapova, T.A.; Zhu, J.; Li, R. Aneuploidy and chromosomal instability: A vicious cycle driving cellular evolution and cancer genome chaos. Cancer Metastasis Rev. 2013, 32, 377-389. [CrossRef]

29. Brownlee, C.; Heald, R. Importin alpha Partitioning to the Plasma Membrane Regulates Intracellular Scaling. Cell 2019, 176, 805-815. [CrossRef]

30. Kalab, P.; Pralle, A.; Isacoff, E.Y.; Heald, R.; Weis, K. Analysis of a RanGTP-regulated gradient in mitotic somatic cells. Nature 2006, 440, 697-701. [CrossRef]

31. Meunier, S.; Vernos, I. K-fibre minus ends are stabilized by a RanGTP-dependent mechanism essential for functional spindle assembly. Nat. Cell Biol. 2011, 13, 1406-1414. [CrossRef]

32. Gregory, P.E.; Gutmann, D.H.; Mitchell, A.; Park, S.; Boguski, M.; Jacks, T.; Wood, D.L.; Jove, R.; Collins, F.S. Neurofibromatosis type 1 gene product (neurofibromin) associates with microtubules. Somat. Cell Mol. Genet. 1993, 19, 265-274. [CrossRef] [PubMed]

33. Bollag, G.; McCormick, F.; Clark, R. Characterization of full-length neurofibromin: Tubulin inhibits Ras GAP activity. EMBO J. 1993, 12, 1923-1927. [CrossRef]

34. Leondaritis, G.; Mangoura, D. Regulation of neurofibromin's GAP-related domain RasGAP activity by a Sec14-homology domain-dependent allosteric switch. In Proceedings of the 61th EEBMB, Alexandroupolis, Greece, 15-17 October 2010; p. 57.

35. Patrakitkomjorn, S.; Kobayashi, D.; Morikawa, T.; Wilson, M.M.; Tsubota, N.; Irie, A.; Ozawa, T.; Aoki, M.; Arimura, N.; Kaibuchi, K.; et al. Neurofibromatosis type 1 (NF1) tumor suppressor, neurofibromin, regulates the neuronal differentiation of PC12 cells via its associating protein, CRMP-2. J. Biol. Chem. 2008, 283, 9399-9413. [CrossRef] [PubMed]

36. Xu, H.; Gutmann, D.H. Mutations in the GAP-related domain impair the ability of neurofibromin to associate with microtubules. Brain Res. 1997, 759, 149-152. [CrossRef]

37. Scheffzek, K.; Ahmadian, M.R.; Wiesmuller, L.; Kabsch, W.; Stege, P.; Schmitz, F.; Wittinghofer, A. Structural analysis of the GAP-related domain from neurofibromin and its implications. EMBO J. 1998, 17, 4313-4327. [CrossRef] [PubMed]

38. D'Angelo, I.; Welti, S.; Bonneau, F.; Scheffzek, K. A novel bipartite phospholipid-binding module in the neurofibromatosis type 1 protein. EMBO Rep. 2006, 7, 174-179. [CrossRef] [PubMed]

39. D'Angelo, F.; Ceccarelli, M.; Tala; Garofano, L.; Zhang, J.; Frattini, V.; Caruso, F.P.; Lewis, G.; Alfaro, K.D.; Bauchet, L.; et al. The molecular landscape of glioma in patients with Neurofibromatosis 1. Nat. Med. 2019, 25, 176-187. [CrossRef]

40. Yap, Y.S.; McPherson, J.R.; Ong, C.K.; Rozen, S.G.; Teh, B.T.; Lee, A.S.; Callen, D.F. The NF1 gene revisited-From bench to bedside. Oncotarget 2014, 5, 5873-5892. [CrossRef]

41. Cancer Genome Atlas Research Network. Comprehensive genomic characterization defines human glioblastoma genes and core pathways. Nature 2008, 455, 1061-1068. [CrossRef] 
42. Koczkowska, M.; Chen, Y.; Callens, T.; Gomes, A.; Sharp, A.; Johnson, S.; Hsiao, M.C.; Chen, Z.; Balasubramanian, M.; Barnett, C.P.; et al. Genotype-Phenotype Correlation in NF1: Evidence for a More Severe Phenotype Associated with Missense Mutations Affecting NF1 Codons 844-848. Am. J. Hum. Genet. 2018, 102, 69-87. [CrossRef] [PubMed]

43. Xu, M.; Xiong, H.; Han, Y.; Li, C.; Mai, S.; Huang, Z.; Ai, X.; Guo, Z.; Zeng, F.; Guo, Q. Identification of Mutation Regions on NF1 Responsible for High- and Low-Risk Development of Optic Pathway Glioma in Neurofibromatosis Type I. Front. Genet. 2018, 9, 270. [CrossRef] [PubMed]

44. Barron, V.A.; Zhu, H.; Hinman, M.N.; Ladd, A.N.; Lou, H. The neurofibromatosis type I pre-mRNA is a novel target of CELF protein-mediated splicing regulation. Nucleic Acids Res. 2010, 38, 253-264. [CrossRef]

45. Andersen, L.B.; Ballester, R.; Marchuk, D.A.; Chang, E.; Gutmann, D.H.; Saulino, A.M.; Camonis, J.; Wigler, M.; Collins, F.S. A conserved alternative splice in the von Recklinghausen neurofibromatosis (NF1) gene produces two neurofibromin isoforms, both of which have GTPase-activating protein activity. Mol. Cell Biol. 1993, 13, 487-495. [CrossRef] [PubMed]

46. Luo, G.; Kim, J.; Song, K. The C-terminal domains of human neurofibromin and its budding yeast homologs Ira1 and Ira2 regulate the metaphase to anaphase transition. Cell Cycle 2014, 13, 2780-2789. [CrossRef] [PubMed]

47. Starinsky-Elbaz, S.; Faigenbloom, L.; Friedman, E.; Stein, R.; Kloog, Y. The pre-GAP-related domain of neurofibromin regulates cell migration through the LIM kinase/cofilin pathway. Mol. Cell Neurosci. 2009, 42, 278-287. [CrossRef]

48. Sherekar, M.; Han, S.W.; Ghirlando, R.; Messing, S.; Drew, M.; Rabara, D.; Waybright, T.; Juneja, P.; O’Neill, H.; Stanley, C.B.; et al. Biochemical and structural analyses reveal that the tumor suppressor neurofibromin (NF1) forms a high-affinity dimer. J. Biol. Chem. 2020, 295, 1105-1119. [CrossRef]

49. Mangoura, D.; Sun, Y.; Li, C.; Singh, D.; Gutmann, D.H.; Flores, A.; Ahmed, M.; Vallianatos, G. Phosphorylation of neurofibromin by PKC is a possible molecular switch in EGF receptor signaling in neural cells. Oncogene 2006, 25, 735-745. [CrossRef]

50. Ozawa, T.; Araki, N.; Yunoue, S.; Tokuo, H.; Feng, L.; Patrakitkomjorn, S.; Hara, T.; Ichikawa, Y.; Matsumoto, K.; Fujii, K.; et al. The neurofibromatosis type 1 gene product neurofibromin enhances cell motility by regulating actin filament dynamics via the Rho-ROCK-LIMK2-cofilin pathway. J. Biol. Chem. 2005, 280, 39524-39533. [CrossRef]

51. Li, C.; Cheng, Y.; Gutmann, D.A.; Mangoura, D. Differential localization of the neurofibromatosis 1 (NF1) gene product, neurofibromin, with the F-actin or microtubule cytoskeleton during differentiation of telencephalic neurons. Brain Res. Dev. Brain Res. 2001, 130, 231-248. [CrossRef]

52. Vandenbroucke, I.; Vandesompele, J.; De Paepe, A.; Messiaen, L. Quantification of NF1 transcripts reveals novel highly expressed splice variants. FEBS Lett. 2002, 522, 71-76. [CrossRef]

53. Zheng, Z.Y.; Anurag, M.; Lei, J.T.; Cao, J.; Singh, P.; Peng, J.; Kennedy, H.; Nguyen, N.C.; Chen, Y.; Lavere, P.; et al. Neurofibromin Is an Estrogen Receptor-alpha Transcriptional Co-repressor in Breast Cancer. Cancer Cell 2020, 37, 387-402. [CrossRef] [PubMed]

54. Stegmeier, F.; Hu, G.; Rickles, R.J.; Hannon, G.J.; Elledge, S.J. A lentiviral microRNA-based system for single-copy polymerase II-regulated RNA interference in mammalian cells. Proc. Natl. Acad. Sci. USA 2005, 102, 13212-13217. [CrossRef] [PubMed]

55. Zeng, Y.; Wagner, E.J.; Cullen, B.R. Both natural and designed micro RNAs can inhibit the expression of cognate mRNAs when expressed in human cells. Mol. Cell 2002, 9, 1327-1333. [CrossRef]

56. Meerbrey, K.L.; Hu, G.; Kessler, J.D.; Roarty, K.; Li, M.Z.; Fang, J.E.; Herschkowitz, J.I.; Burrows, A.E.; Ciccia, A.; Sun, T.; et al. The pINDUCER lentiviral toolkit for inducible RNA interference in vitro and in vivo. Proc. Natl. Acad. Sci. USA 2011, 108, 3665-3670. [CrossRef]

57. Tsirimonaki, E.; Fedonidis, C.; Pneumaticos, S.G.; Tragas, A.A.; Michalopoulos, I.; Mangoura, D. PKCepsilon signalling activates ERK1/2, and regulates aggrecan, ADAMTS5, and miR377 gene expression in human nucleus pulposus cells. PLoS ONE 2013, 8, e82045. [CrossRef]

58. Livak, K.J.; Schmittgen, T.D. Analysis of relative gene expression data using real-time quantitative PCR and the 2(-Delta Delta C(T)) Method. Methods 2001, 25, 402-408. [CrossRef]

59. Karouzaki, S.; Peta, C.; Tsirimonaki, E.; Mangoura, D. PKCepsilon-dependent H-Ras activation encompasses the recruitment of the RasGEF SOS1 and of the RasGAP neurofibromin in the lipid rafts of embryonic neurons. Neurochem. Int. 2019, 131, 104582. [CrossRef] 
60. Leondaritis, G.; Petrikkos, L.; Mangoura, D. Regulation of the Ras-GTPase activating protein neurofibromin by C-tail phosphorylation: Implications for protein kinase C/Ras/extracellular signal-regulated kinase 1/2 pathway signaling and neuronal differentiation. J. Neurochem. 2009, 109, 573-583. [CrossRef]

61. Schneider, C.A.; Rasband, W.S.; Eliceiri, K.W. NIH Image to ImageJ: 25 years of image analysis. Nat. Methods 2012, 9, 671-675. [CrossRef]

62. Born, M.; Wolf, E. Principles of Optics; Cambridge University Press: Cambridge, UK, 2003.

63. Barlow, A.L.; Macleod, A.; Noppen, S.; Sanderson, J.; Guerin, C.J. Colocalization analysis in fluorescence micrographs: Verification of a more accurate calculation of pearson's correlation coefficient. Microsc. Microanal. 2010, 16, 710-724. [CrossRef]

64. Costes, S.V.; Daelemans, D.; Cho, E.H.; Dobbin, Z.; Pavlakis, G.; Lockett, S. Automatic and quantitative measurement of protein-protein colocalization in live cells. Biophys. J. 2004, 86, 3993-4003. [CrossRef] [PubMed]

65. Ferreira, T.A.; Blackman, A.V.; Oyrer, J.; Jayabal, S.; Chung, A.J.; Watt, A.J.; Sjostrom, P.J.; van Meyel, D.J. Neuronal morphometry directly from bitmap images. Nat. Methods 2014, 11, 982-984. [CrossRef] [PubMed]

66. Longair, M.H.; Baker, D.A.; Armstrong, J.D. Simple Neurite Tracer: Open source software for reconstruction, visualization and analysis of neuronal processes. Bioinformatics 2011, 27, 2453-2454. [CrossRef] [PubMed]

67. Godin, F.; Villette, S.; Vallee, B.; Doudeau, M.; Morisset-Lopez, S.; Ardourel, M.; Hevor, T.; Pichon, C.; Benedetti, H. A fraction of neurofibromin interacts with PML bodies in the nucleus of the CCF astrocytoma cell line. Biochem. Biophys. Res. Commun. 2012, 418, 689-694. [CrossRef] [PubMed]

68. Etienne-Manneville, S.; Hall, A. Cdc42 regulates GSK-3beta and adenomatous polyposis coli to control cell polarity. Nature 2003, 421, 753-756. [CrossRef] [PubMed]

69. Friedl, P.; Alexander, S. Cancer invasion and the microenvironment: Plasticity and reciprocity. Cell 2011, 147, 992-1009. [CrossRef]

70. Magidson, V.; O'Connell, C.B.; Loncarek, J.; Paul, R.; Mogilner, A.; Khodjakov, A. The spatial arrangement of chromosomes during prometaphase facilitates spindle assembly. Cell 2011, 146, 555-567. [CrossRef]

71. Walczak, C.E.; Zong, H.; Jain, S.; Stout, J.R. Spatial regulation of astral microtubule dynamics by Kif18B in PtK cells. Mol. Biol. Cell 2016, 27, 3021-3030. [CrossRef]

72. Byrne, A.T.; Alferez, D.G.; Amant, F.; Annibali, D.; Arribas, J.; Biankin, A.V.; Bruna, A.; Budinska, E.; Caldas, C.; Chang, D.K.; et al. Interrogating open issues in cancer precision medicine with patient-derived xenografts. Nat. Rev. Cancer 2017, 17, 254-268. [CrossRef]

73. Yde, C.W.; Olsen, B.B.; Meek, D.; Watanabe, N.; Guerra, B. The regulatory beta-subunit of protein kinase CK2 regulates cell-cycle progression at the onset of mitosis. Oncogene 2008, 27, 4986-4997. [CrossRef] [PubMed]

74. Phan, V.T.; Ding, V.W.; Li, F.; Chalkley, R.J.; Burlingame, A.; McCormick, F. The RasGAP proteins Ira2 and neurofibromin are negatively regulated by Gpb1 in yeast and ETEA in humans. Mol. Cell Biol. 2010, 30, 2264-2279. [CrossRef] [PubMed]

75. Kweh, F.; Zheng, M.; Kurenova, E.; Wallace, M.; Golubovskaya, V.; Cance, W.G. Neurofibromin Physically Interacts With the N-Terminal Domain of Focal Adhesion Kinase. Mol. Carcinog. 2009, 48, 1005-1017. [CrossRef] [PubMed]

76. Fukata, Y.; Itoh, T.J.; Kimura, T.; Menager, C.; Nishimura, T.; Shiromizu, T.; Watanabe, H.; Inagaki, N.; Iwamatsu, A.; Hotani, H.; et al. CRMP-2 binds to tubulin heterodimers to promote microtubule assembly. Nat. Cell Biol 2002, 4, 583-591. [CrossRef]

77. Kawano, Y.; Yoshimura, T.; Tsuboi, D.; Kawabata, S.; Kaneko-Kawano, T.; Shirataki, H.; Takenawa, T.; Kaibuchi, K. CRMP-2 is involved in kinesin-1-dependent transport of the Sra-1/WAVE1 complex and axon formation. Mol. Cell Biol. 2005, 25, 9920-9935. [CrossRef]

78. Lin, P.C.; Chan, P.M.; Hall, C.; Manser, E. Collapsin response mediator proteins (CRMPs) are a new class of microtubule-associated protein (MAP) that selectively interacts with assembled microtubules via a taxol-sensitive binding interaction. J. Biol. Chem. 2011, 286, 41466-41478. [CrossRef]

79. Kadavath, H.; Hofele, R.V.; Biernat, J.; Kumar, S.; Tepper, K.; Urlaub, H.; Mandelkow, E.; Zweckstetter, M. Tau stabilizes microtubules by binding at the interface between tubulin heterodimers. Proc. Natl. Acad. Sci. USA 2015, 112, 7501-7506. [CrossRef]

80. Khodjakov, A.; Cole, R.W.; Oakley, B.R.; Rieder, C.L. Centrosome-independent mitotic spindle formation in vertebrates. Curr. Biol. 2000, 10, 59-67. [CrossRef] 
81. Mahoney, N.M.; Goshima, G.; Douglass, A.D.; Vale, R.D. Making microtubules and mitotic spindles in cells without functional centrosomes. Curr. Biol. 2006, 16, 564-569. [CrossRef]

82. Petry, S.; Groen, A.C.; Ishihara, K.; Mitchison, T.J.; Vale, R.D. Branching microtubule nucleation in Xenopus egg extracts mediated by augmin and TPX2. Cell 2013, 152, 768-777. [CrossRef]

83. O'Connell, C.B.; Khodjakov, A.L. Cooperative mechanisms of mitotic spindle formation. J. Cell Sci. 2007, 120, 1717-1722. [CrossRef] [PubMed]

84. Wiese, C.; Zheng, Y. A new function for the gamma-tubulin ring complex as a microtubule minus-end cap. Nat. Cell Biol. 2000, 2, 358-364. [CrossRef]

85. Verollet, C.; Colombie, N.; Daubon, T.; Bourbon, H.M.; Wright, M.; Raynaud-Messina, B. Drosophila melanogaster gamma-TuRC is dispensable for targeting gamma-tubulin to the centrosome and microtubule nucleation. J. Cell Biol. 2006, 172, 517-528. [CrossRef]

86. Consolati, T.; Locke, J.; Roostalu, J.; Chen, Z.A.; Gannon, J.; Asthana, J.; Lim, W.M.; Martino, F.; Cvetkovic, M.A.; Rappsilber, J.; et al. Microtubule Nucleation Properties of Single Human gammaTuRCs Explained by Their Cryo-EM Structure. Dev. Cell 2020, 53, 603-617. [CrossRef] [PubMed]

87. Gard, D.L.; Kirschner, M.W. A microtubule-associated protein from Xenopus eggs that specifically promotes assembly at the plus-end. J. Cell Biol. 1987, 105, 2203-2215. [CrossRef] [PubMed]

88. Kronja, I.; Kruljac-Letunic, A.; Caudron-Herger, M.; Bieling, P.; Karsenti, E. XMAP215-EB1 interaction is required for proper spindle assembly and chromosome segregation in Xenopus egg extract. Mol. Biol. Cell 2009, 20, 2684-2696. [CrossRef] [PubMed]

89. Ringhoff, D.N.; Cassimeris, L. Stathmin regulates centrosomal nucleation of microtubules and tubulin dimer/polymer partitioning. Mol. Biol. Cell 2009, 20, 3451-3458. [CrossRef] [PubMed]

90. Zhai, Y.; Kronebusch, P.J.; Simon, P.M.; Borisy, G.G. Microtubule dynamics at the G2/M transition: Abrupt breakdown of cytoplasmic microtubules at nuclear envelope breakdown and implications for spindle morphogenesis. J. Cell Biol. 1996, 135, 201-2014. [CrossRef]

91. Plessner, M.; Knerr, J.; Grosse, R. Centrosomal Actin Assembly Is Required for Proper Mitotic Spindle Formation and Chromosome Congression. iScience 2019, 15, 274-281. [CrossRef]

92. Stiff, T.; Echegaray-Iturra, F.R.; Pink, H.J.; Herbert, A.; Reyes-Aldasoro, C.C.; Hochegger, H. Prophase-Specific Perinuclear Actin Coordinates Centrosome Separation and Positioning to Ensure Accurate Chromosome Segregation. Cell Rep. 2020, 31, 107681. [CrossRef]

93. Morin, X.; Bellaiche, Y. Mitotic spindle orientation in asymmetric and symmetric cell divisions during animal development. Dev. Cell 2011, 21, 102-119. [CrossRef] [PubMed]

94. Roth, D.; Fitton, B.P.; Chmel, N.P.; Wasiluk, N.; Straube, A. Spatial positioning of EB family proteins at microtubule tips involves distinct nucleotide-dependent binding properties. J. Cell Sci. 2018, 132. [CrossRef] [PubMed]

95. Iimori, M.; Watanabe, S.; Kiyonari, S.; Matsuoka, K.; Sakasai, R.; Saeki, H.; Oki, E.; Kitao, H.; Maehara, Y. Phosphorylation of EB2 by Aurora B and CDK1 ensures mitotic progression and genome stability. Nat. Commun. 2016, 7, 11117. [CrossRef] [PubMed]

96. Goldspink, D.A.; Gadsby, J.R.; Bellett, G.; Keynton, J.; Tyrrell, B.J.; Lund, E.K.; Powell, P.P.; Thomas, P.; Mogensen, M.M. The microtubule end-binding protein EB2 is a central regulator of microtubule reorganisation in apico-basal epithelial differentiation. J. Cell Sci. 2013, 126, 4000-4014. [CrossRef] [PubMed]

97. Malerod, L.; Le Borgne, R.; Lie-Jensen, A.; Eikenes, A.H.; Brech, A.; Liestol, K.; Stenmark, H.; Haglund, K. Centrosomal ALIX regulates mitotic spindle orientation by modulating astral microtubule dynamics. EMBO J. 2018, 37. [CrossRef] [PubMed]

98. Ai, E.; Poole, D.S.; Skop, A.R. RACK-1 directs dynactin-dependent RAB-11 endosomal recycling during mitosis in Caenorhabditis elegans. Mol. Biol. Cell 2009, 20, 1629-1638. [CrossRef]

99. Rizk, R.S.; Bohannon, K.P.; Wetzel, L.A.; Powers, J.; Shaw, S.L.; Walczak, C.E. MCAK and paclitaxel have differential effects on spindle microtubule organization and dynamics. Mol. Biol. Cell 2009, 20, 1639-1651. [CrossRef]

100. van Heesbeen, R.; Raaijmakers, J.A.; Tanenbaum, M.E.; Halim, V.A.; Lelieveld, D.; Lieftink, C.; Heck, A.J.R.; Egan, D.A.; Medema, R.H. Aurora A, MCAK, and Kif18b promote Eg5-independent spindle formation. Chromosoma 2017, 126, 473-486. [CrossRef] 
101. Kitamura, E.; Tanaka, K.; Komoto, S.; Kitamura, Y.; Antony, C.; Tanaka, T.U. Kinetochores generate microtubules with distal plus ends: Their roles and limited lifetime in mitosis. Dev. Cell 2010, 18, 248-259. [CrossRef]

102. Goshima, G.; Mayer, M.; Zhang, N.; Stuurman, N.; Vale, R.D. Augmin: A protein complex required for centrosome-independent microtubule generation within the spindle. J. Cell Biol. 2008, 181, 421-429. [CrossRef]

103. Song, J.G.; King, M.R.; Zhang, R.; Kadzik, R.S.; Thawani, A.; Petry, S. Mechanism of how augmin directly targets the gamma-tubulin ring complex to microtubules. J. Cell Biol. 2018, 217, 2417-2428. [CrossRef] [PubMed]

104. Kajtez, J.; Solomatina, A.; Novak, M.; Polak, B.; Vukusic, K.; Rudiger, J.; Cojoc, G.; Milas, A.; Sumanovac Sestak, I.; Risteski, P.; et al. Overlap microtubules link sister k-fibres and balance the forces on bi-oriented kinetochores. Nat. Commun. 2016, 7, 10298. [CrossRef] [PubMed]

105. Jdey, W.; Thierry, S.; Popova, T.; Stern, M.H.; Dutreix, M. Micronuclei Frequency in Tumors Is a Predictive Biomarker for Genetic Instability and Sensitivity to the DNA Repair Inhibitor AsiDNA. Cancer Res. 2017, 77, 4207-4216. [CrossRef] [PubMed]

106. Crasta, K.; Ganem, N.J.; Dagher, R.; Lantermann, A.B.; Ivanova, E.V.; Pan, Y.; Nezi, L.; Protopopov, A.; Chowdhury, D.; Pellman, D. DNA breaks and chromosome pulverization from errors in mitosis. Nature 2012, 482, 53-58. [CrossRef] [PubMed]

107. Liu, S.; Kwon, M.; Mannino, M.; Yang, N.; Renda, F.; Khodjakov, A.; Pellman, D. Nuclear envelope assembly defects link mitotic errors to chromothripsis. Nature 2018, 561, 551-555. [CrossRef] [PubMed]

Publisher's Note: MDPI stays neutral with regard to jurisdictional claims in published maps and institutional affiliations. 